\section{Nature}

December 2008 ; Volume 456 (7224) : Pages 938-941

http://dx.doi.org/10.1038/nature07573

Copyright (c) 2008 Nature Publishing Group

The original publication is available at http://www.nature.com
Archimer http://www.ifremer.fr/docelec/ Archive Institutionnelle de l'Ifremer

\title{
How supercontinents and superoceans affect seafloor roughness
}

\author{
Joanne M. Whittaker ${ }^{1,5,{ }^{*}, \text { R. Dietmar Müller }}{ }^{1}$, Walter R. Roest ${ }^{2}$, Paul Wessel $^{3}$ \& Walter H. F. Smith ${ }^{4}$ \\ ${ }^{1}$ School of Geosciences, Build. F09, The University of Sydney, N.S.W 2006, Australia \\ 2 Département des Géosciences Marines, Ifremer, Centre de Brest, BP 70, 29280 Plouzané, France \\ ${ }^{3}$ Department of Geology and Geophysics, SOEST, University of Hawaii at Mānoa, Honolulu, HI 96822, USA \\ ${ }^{4}$ National Oceanic and Atmospheric Administration, Silver Spring, Maryland 20910, USA \\ ${ }^{5}$ Present address: GETECH, Kitson House, Elmete Hall, Elmete Lane, Leeds LS8 2LJ, UK
}

*: Corresponding author : Joanne M. Whittaker, email address : jw@getech.com

\begin{abstract}
:
Seafloor roughness varies considerably across the world's ocean basins and is fundamental to controlling the circulation and mixing of heat in the ocean ${ }^{1}$ and dissipating eddy kinetic energy ${ }^{2}$. Models derived from analyses of active mid-ocean ridges suggest that ocean floor roughness depends on seafloor spreading rates (e.g. ${ }^{3}$ ), with rougher basement forming below a spreading rate threshold of $30-35 \mathrm{~mm} / \mathrm{yr}^{4,5}$, as well as on the local interaction of mid-ocean ridges with mantle plumes or coldspots $^{6}$. Our global analysis of marine gravity-derived roughness, sediment thickness, seafloor isochrons, and palaeo-spreading rates ${ }^{7}$ of Cretaceous to Cenozoic ridge flanks reveals that, after eliminating spreading rate and sediment thickness related effects, residual roughness anomalies of 5$20 \mathrm{mGal}$ remain over large swaths of ocean floor. An analysis of roughness as a function of palaeospreading directions and isochron orientations ${ }^{7}$ reveals that most of the observed excess roughness is not related to spreading obliquity, as this effect is restricted to relatively rare occurrences of very high obliquity angles $\left(>45^{\circ}\right)$. Cretaceous Atlantic ocean floor, formed over mantle previously overlain by the Pangaea supercontinent, displays anomalously low roughness away from mantle plumes and independent of spreading rates. We attribute this observation to a sub-Pangaean supercontinental mantle temperature anomaly ${ }^{8}$ leading to slightly thicker than normal Late Jurassic and Cretaceous Atlantic crust ${ }^{9}$, reduced brittle fracturing and smoother basement relief. In contrast, ocean crust formed above Pacific superswells ${ }^{10}$, likely reflecting metasomatized lithosphere underlain by mantle at only slightly elevated temperatures ${ }^{11}$, is not associated with basement roughness anomalies. These results highlight a fundamental difference in the nature of large-scale mantle upwellings below supercontinents and superoceans, and their impact on oceanic crustal accretion.
\end{abstract}


The relationship between spreading rates and marine basement roughness has predominantly been determined through analysis of near-zero aged crust on individual profiles across mid-ocean ridges using short wavelength gravity ${ }^{3,4}$ or bathymetry. This relationship was also found to hold for off-axis oceanic crust at all ages ${ }^{5}$. Short wavelength roughness in gravity anomalies ( $\sim 20-160 \mathrm{~km}$ wavelength) reflects the roughness of oceanic basement topography ${ }^{4}$. Here we use a 2-minute gravity anomaly grid downward continued onto the seafloor based on Sandwell and Smith ${ }^{12}$ (Supp. Fig. 1) to create a root mean square (RMS) marine gravity roughness grid (Fig 1) using a $100 \mathrm{~km}$ wide Gaussian filter with seamounts and oceanic plateaus masked (Supp. Fig. 2).

Half-spreading rate and sediment cover (Supp. Fig 1) strongly influence basement roughness. These factors are removed to examine the role of other potential factors such as spreading obliquity, and mantle temperature, and mantle fertility on basement roughness. Each kilometre of sediment ${ }^{13}$ results in a $\sim 14 \%$ decrease in gravity roughness (Fig. 2a). Global half-spreading rates ${ }^{7}$ (a) faster than $35 \mathrm{~mm} / \mathrm{yr}$ result in low gravity roughness $(-7 \mathrm{mGal})$, (b) between $35-15 \mathrm{~mm} / \mathrm{yr}$ result in increasingly rough and variable gravity roughness, and (c) slower than $15 \mathrm{~mm} / \mathrm{yr}$ form high-amplitude gravity roughness ( $\sim 15 \mathrm{mGal})$ (Fig. $2 \mathrm{~b})$. These results differ from previous findings ${ }^{4,5}$ that suggest gravity roughness continues to increase with decreasing spreading rates $<15$ $\mathrm{mm} / \mathrm{yr}$.

Our results confirm that the relationship between spreading rate and basement roughness is consistent with the 'magma lens' model of mid-ocean ridge formation ${ }^{6}$, where decreasing spreading rates lead to increasing lens depth and decreased melt production, with a relatively rapid transition from a lens to no-lens situation. Our global results show that roughness is insensitive to spreading rate at rates $>35 \mathrm{~mm} / \mathrm{yr}$ and < $15 \mathrm{~mm} / \mathrm{yr}$, likely representing lens and no-lens situations, respectively, with a transitional stage occurring as spreading rates drop from 30-35 to $15 \mathrm{~mm} / \mathrm{yr}$. Crust created at rates $<15 \mathrm{~mm} / \mathrm{yr}$ is approximately twice as rough as crust created at rates $>$ $35 \mathrm{~mm} / \mathrm{yr}$, consistent with thermo-tectonic cyclicity at slow spreading rates ${ }^{14}$.

Residual roughness (Fig. 3) is calculated by removing spreading rate and sediment thickness effects (Fig. 2) from the RMS-gravity roughness grid (Fig. 1) to investigate how spreading obliquity and mantle conditions influence basement roughness. Higher angles of spreading obliquity are related to increasing ridge segmentation ${ }^{14,15}$ and seismicity ${ }^{15}$, both due to increased brittle fracturing at higher spreading angles ${ }^{15}$. Spreading obliquity has also been found to influence ridge morphology by decreasing effective spreading rates proportionally to $\cos (\theta)^{16}$, where $\theta$ is the angle of obliquity.

To investigate the relationship between spreading obliquity and basement roughness we create regional 2-minute spreading obliquity grids for ten regions (intentionally excluding triple-junctions, small/temporary spreading centres, back-arc basins and areas with complex spreading histories: Fig. 3 and Supp. Fig. 5-14) by calculating the difference between the regional plate motion direction and the normal to the regional mid-ocean ridge strike in 5 million year (Myr) stages. Our results show that for spreading obliquities $<45^{\circ}$, variation of residual roughness with spreading obliquity fits a roughness curve that includes the effective reduction in spreading rate caused by oblique spreading (Figure 3, inset). However, our analysis also reveals that for obliquities $>45^{\circ}$ residual roughness increases much more rapidly, indicating that an additional mechanism, likely brittle fracturing, causes increased roughness at high spreading obliquities. 
Analysis of residual roughness is carried out for each selected spreading system (Figure 4) based on spreading rate, sediment thickness and RMS-gravity roughness (see Supp. Figure 15 for an example of how the sediment thickness-roughness relationships improves the predicted roughness for individual flanks of the South Atlantic spreading system). Only in the North and South Pacific is basement roughness accurately predicted using spreading rate and sediment thickness. With the additional removal of roughness related to spreading obliquity, the roughness of the Southeast Indian Ridge flanks is well predicted, while the misfit for the South American-Antarctic Ridge is reduced. However, spreading rate, sediment thickness and spreading obliquity do not accurately predict basement roughness for the remaining regions that exhibit long-term deviations of 5-20 mGal over periods $>40$ Myr and in many cases $>60 \mathrm{Myr}$ (Fig. 4).

Relatively smooth basement is predicted for the Australian-Antarctic Discordance (AAD) based on spreading rates of 35-40 mm/yr since $\sim 40$ Myr ago. However, the AAD exhibits basement up to $8 \mathrm{mGal}$ rougher than predicted (Fig. 4e). Crustal thickness in the $A A D$ is $2-4 \mathrm{~km}$ thinner than adjacent crust, implying a $150^{\circ} \mathrm{C}$ decrease in mantle temperature $^{17}$. Also, the AAD is located at the site of a palaeo-subduction zone, with current lavas likely sourced from depleted magmas derived from subducted oceanic crust $^{18}$. Mantle fertility additionally affects the bulk extent of melting ${ }^{19,20}$, with depleted mantle producing lower melt volumes ${ }^{21}$ and thus rougher basement. Both cool mantle temperatures and low mantle fertility have resulted in rough basement in the AAD despite relatively fast spreading rates over the past $15 \mathrm{Myr}^{22}$.

We suggest that remaining long-term residual roughness variations, after the removal of roughness caused by variations in spreading rate and sediment cover, are attributable to the temperature and fertility conditions of the underlying mantle. Cretaceous (80-130 Myr) oceanic crust is smoother than expected, expressed by negative residual roughness (-3 to $-9 \mathrm{mGal})$, mainly in the Central and South Atlantic regions. These regions formed at slow spreading rates $(<30 \mathrm{~mm} / \mathrm{yr})$ during the initial stages of continental dispersal and are associated with pre-breakup magmatism that has been suggested to be unrelated to plume activity ${ }^{8,23}$. Smoother than expected crust occurs over a vast spatial and temporal domain (over $9000 \mathrm{~km}$ in length and over $\sim 50$ million years), supporting a non-plume related formation mechanism.

Previously, anomalously thick Cretaceous crust on the North American side of the Atlantic has been attributed to a mantle plume influence ${ }^{9}$. However, our analysis shows that both sides of the Atlantic have Cretaceous crust that is smoother than expected (Supp. Fig. 16), over an area too vast to be related to hotspot related anomalous mantle. We propose that the majority of preserved Cretaceous oceanic crust accreted from anomalously hot mantle supercontinent mantle following Pangaea break-up. Continental aggregation may cause an enlargement of mantle convection wavelengths leading to mantle temperatures up to $100^{\circ} \mathrm{C}$ hotter than normal beneath supercontinents ${ }^{8}$. This mantle thermal anomaly is dissipated through sea floor spreading following supercontinent break-up. The anomalously hot mantle would lead to thicker crust and reduced brittle fracturing even under slow spreading conditions.

The North Pacific is the only region with substantial volumes of preserved $80-130 \mathrm{Myr}$ old crust that did not form through supercontinent break-up. Here spreading rate and sediment thickness accurately predict basement roughness despite the influence of the Cretaceous North Pacific Darwin Rise superswell ( 120-85 Myr), which may be expected to lead to anomalously smooth basement due to increased heat flow and partial melting ${ }^{10}$. Presently the South Pacific is underlain by the similar South Pacific 
superswell $^{10}$, which also does not lead to smoother (or rougher) than expected basement. Our observations suggest that Pacific superswells, while causing widespread shallowing of the seafloor ${ }^{10}$ and widespread, small-scale alkaline volcanism ${ }^{11}$ do not strongly influence accretionary processes at mid-ocean ridges. This may reflect metasomatized Pacific superswell lithosphere underlain by mantle at only slightly elevated temperatures, having a negligible effect on mid-ocean ridge accretionary processes. South Pacific superswell initiation has been suggested to reflect a slab-avalanche event leading to slab detachment at the mantle transition zone $^{11}$. However, a recent plate kinematic model ${ }^{24}$ leads to the suggestion that the South Pacific superswell was triggered by the well-mapped Eocene plate reorganization, associated with Izanagi-Pacific ridge subduction and subduction initiation along Tonga-Kermadec and the Marianas. The descending slabs of these newly formed subduction zones likely progressively impeded the southwest flow of subPacific mantle ${ }^{24}$, known to halt at $47 \mathrm{Ma}^{25}$ and triggering an upper mantle return flow ultimately causing anomalously shallow regional seafloor. Our hypothesis provides a mechanism that explains the on-going nature of the South Pacific Superswell, including a lacking influence on seafloor roughness, as opposed a temporal, catastrophic mantle avalanche mechanism.

Our results provide observational evidence for a fundamental difference between the long-term mantle evolution below supercontinents and superoceans. Supercontinent assembly may lead to a $100^{\circ}$ warming of sub-continental mantle, whereas associated suboceanic mantle stays relatively constant in temperature ${ }^{8}$. During supercontinent dispersal, newly formed spreading ridges initially sample anomalously hot mantle, whereas normal ocean crust in the antipodal superocean is not similarly affected. Considering that continental breakup occurred in the central North Atlantic at about 175 $\mathrm{Ma}^{26}$, and that we observe anomalously smooth regional oceanic basement roughness until $80 \mathrm{Ma}$, it takes nearly 100 million years for supercontinental mantle warming to dissipate.

Many of the spreading systems analyzed here experienced a shift from smoother to rougher than expected basement at $\sim 70 \mathrm{Myr}$ ago (central and southern Atlantic systems) and $\sim 50$ Myr ago (western Indian systems). This may partly reflect the gradual dissipation of a supercontinent related thermal anomaly, but this alone would not account for a shift to a positive roughness anomaly. Upper mantle depletion is known to reduce melt volumes ${ }^{21}$. The western Indian and central and southern Atlantic mid-ocean ridges are relatively distal to large mantle plumes, resulting in poor upper mantle replenishment because of their dependence on slow, localised mantle upwellings $^{27}$. An unusual geochemical signature indicates that depleted rather than cold mantle is at least partly responsible for anomalously rough basement at the Southwest Indian Ridge ${ }^{21}$. We interpret anomalously rough basement formed during the Cenozoic in the Atlantic and western Indian oceans as reflecting a gradual migration of mid-ocean ridges away from major mantle upwellings ${ }^{28}$, depriving spreading centres of asthenospheric replenishment.

Contrary to previous studies our results demonstrate that mantle temperature/fertility and spreading obliquity can dominate spreading rate effects on oceanic basement roughness. As ocean mixing is strongly influenced by seafloor topography, realistic palaeoceanographic simulations depend on reconstructed ocean basin topography, including palaeo-gateways underlain by now subducted crust. Our model provides a predictive framework for reconstructing more realistic maps of ancient ocean basins - a necessary prerequisite for understanding ocean circulation and mixing through time. 


\section{Methods Summary}

We high-pass filter the downward-continued gravity grid using a Gaussian filter of 100 $\mathrm{km}$ width, then calculate a Gaussian-weighted RMS for these residuals with the same filter width (Fig. 1). Short wavelength roughness in gravity anomalies ( $20-160 \mathrm{~km}$ wavelength) reflects the roughness of oceanic basement topography ${ }^{5}$. By computing a roughness grid based on a filter width of $160 \mathrm{~km}$ following Smith $^{5}$ we find that many basement tectonic features are not well resolved (Supp. Fig 4). This reflects that the vast majority of structural features of the seafloor such as abyssal hills, fracture zone troughs and ridges have wavelengths significantly smaller than $160 \mathrm{~km}$. We select a $100 \mathrm{~km}$ filter width in order to better resolve spatial variations in seafloor roughness on relatively small scales (Supp. Fig. 4). The spreading rate dependence of roughness is analysed here in 5 million year intervals. Intraplate seamount trails and large igneous provinces, rough features formed by non-accretionary processes, are masked from the basement roughness grid using a mask based on Wessel's ${ }^{28}$ seamount catalogue and Coffin and Eldholm's ${ }^{29}$ outlines of oceanic plateaus. The mapped seamount radii are multiplied by a factor of 2.5 to mask out flexural effects from seamount emplacement. Without this masking the roughness becomes biased by intraplate volcanism unrelated to mid-ocean ridge processes (Supp. Fig. 2).

\section{References}

1 Polzin, K. L., Toole, J. M., Ledwell, J. R., and Schmitt, R. W., Spatial variability of turbulent mixing in the abyssal ocean. Science 276, 93-96 (1997).

2 Gille, S. T., Yale, M. M., and Sandwell, D. T., Global correlation of mesoscale ocean variability with seafloor roughness from satellite altimetry. Geophysical Research Letters 27, 1251-1254 (2000).

3 Malinverno, A., Inverse square-root dependence of mid-ocean-ridge flank roughness on spreading rate. Nature 352, 58-60 (1991).

4 Small, C. and Sandwell, D. T., An abrupt change in ridge-axis gravity with spreading rate. Journal of Geophysical Research 94, 17383-17392 (1989).

5 Smith, W. H. F., Seafloor tectonic fabric from satellite altimetry. Annual Review of Earth and Planetary Sciences 26, 697-747 (1998).

6 Chen, Y.J., in Ophiolites and Oceanic Crust: New Insights from Field Studies and the Ocean Drilling Program, edited by Dilek, Y., Moores, E. M., Elthon, D. et al. (Geological Society of America, Denver, 2000), Vol. Special Paper 349, pp. 161-179.

$7 \quad$ Müller, R.D., Sdrolias, M., Gaina, C., and Roest, W.R., Age, spreading rates and spreading asymmetry of the world's ocean crust. Geochemistry, Geophysics, Geosystems 9, doi:10.1029/2007GC001743 (2008).

8 Coltice, N., Phillips, B.R., Bertrand, H., Ricard, Y., and Rey, P., Global warming of the mantle at the origin of flood basalts over supercontinents. Geology 35, 391-394 (2007).

9 Minshull, T. A., On the roughness of Mesozoic oceanic crust in the western North Atlantic. Geophysical Journal International 136, 286-290 (1999).

10 McNutt, M.K., Superswells. Reviews of Geophysics 36, 211-244 (1998).

11 Finn, C. A., Müller, R. D., and Panter, K. S., A Cenozoic diffuse alkaline magmatic province (DAMP) in the southwest Pacific without rift or plume origin. Geochemistry Geophysics Geosystems 6, Q02005, doi:02010.01029/02004GC000723 (2005).

12 Sandwell, D. T. and Smith, W. H. F., Retracking ERS-1 altimeter waveforms for optimal gravity field recovery Geophysical Journal International 163, 79-89 (2005). 
13 Divins, D. L., (National Geophysical Data Center, 2004).

14 Abelson, M. and Agnon, A., Mechanics of oblique spreading and ridge segmentation. Earth Planet Sci Lett 148, 405-421 (1997).

15 de Alteriis, G., Gilg-Capar, L., and Olivet, J. L., Matching satellite-derived gravity signatures and seismicity patterns along mid-ocean ridges. Terra Nova 10, 177182 (1998).

16 Montesi, L. G. J. and Behn, M. D., Mantle flow and melting underneath oblique and ultraslow mid-ocean ridges. Geophysical Research Letters 34, doi: 10.1029/2007GL031067 (2007).

17 West, B. P., Sempere, J. C., Pyle, D. G., Phipps Morgan, J., and Christie, D. M., Evidence for variable upper mantle temperature and crustal thickness in and near the Australian-Antarctic Discordance. Earth Planet Sci Lett 128, 135-153 (1994).

18 Ritzwoller, M. H., Shapiro, N. M., and Leahy, G. M., A resolved mantle anomaly as the cause of the Australian-Antarctic Discordance. J. Geophys. Res. 108, 25592559 (2003).

19 Langmuir, C.H., Klein, E.M., and Plank, T., in Mantle Flow and Melt Generation at Mid-Ocean Ridges, AGU Geophysical Monograph, edited by Phipps Morgan, J., Blackman, D.K., and Sinton, J.M. (1992), Vol. 71, pp. 183-280.

20 Klein, E.M. and Langmuir, C.H., Global correlations of ocean ridge basalt chemistry with axial depth and crustal thickness. Journal of Geophysical Research 92 (1987).

21 Meyzen, C. M., Toplis, M. J., Humler, E., Ludden, J. N., and Mevel, C., A discontinuity in mantle composition benearth the southwest Indian ridge. Nature 42 , 731-733 (2003).

22 Marks, K.M., Stock, J.M., and Quinn, K.J., Evolution of the Australian-Antarctic discordance since Miocene time. J. Geophys. Res. 104, 4697-4981 (1999).

23 McHone, J., Non-plume magmatism and rifting during the opening of the central Atlantic Ocean Tectonophysics 316, 287-296 (2000).

24 Whittaker, J. et al., Major Australian-Antarctic plate reorganization at HawaiianEmperor bend time. Science 318, 83-86 (2007).

25 Tarduno, J. A. et al., The Emperor Seamounts: Southward Motion of the Hawaiian Hotspot Plume in Earth's Mantle. Science 301, 1064-1069 (2003).

26 Klitgord, K. and Schouten, H., in The Western North Atlantic Region, DNAG, edited by Vogt, P. R. and Tucholke, B. E. (Geol. Soc. Am. Boulder, CO, United States, 1986), Vol. M, pp. 351-378.

27 Meyzen, C. M. et al., Isotopic portrayal of the Earth's upper mantle flow field. Nature 447 (2007).

28 Wessel, P., Global distribution of seamounts inferred from gridded Geosat/ERS1 altimetry. Journal of Geophysical Research-Solid Earth 106, 19431-19441 (2001).

29 Coffin, M. F. and Eldholm, O., Large Igneous Provinces: Crustal Structure, Dimensions, and External Consequences. Reviews of Geophysics 32, 1-36 (1994).

\section{Acknowledgements}

We would like to thank two anonymous reviewers for constructive reviews that improved this paper considerably. 


\section{Author Contributions}

WHFS: Gravity field production, the downward continuation, contribution to early ideas on roughness and the first use of downward-continued gravity to study off-axis variations of roughness with spreading rate [in Smith, ${ }^{5}$.

PW: Creation of seamount/LIP mask (essential for masking out anomalous ocean floor) and also he made major extensions to grdfilter to compute RMS roughness on a Mercator projected grid.

WR: An initiator of the project who initially explored the effect of both rate and spreading obliquity on roughness, and wrote various fortran programs to explore these effects.

RDM: An initiator this project, and PhD supervisor of JW, who conceived of the idea that supercontinent and superocean effects may drive large-scale roughness anomalies. He and WR laid the groundwork of this project when they first started exploring workflows to analyse the dependence of seafloor roughness on factors other than spreading rate. He and WR created initial roughness grids, which were improved by the approach implemented by JW.

JW: Executed the entire project, and combined the various existing ideas and program fragments together into a coherent workflow that allowed systematic testing of ideas and quantification of the supercontinent/superocean hypothesis.

\section{Figures}

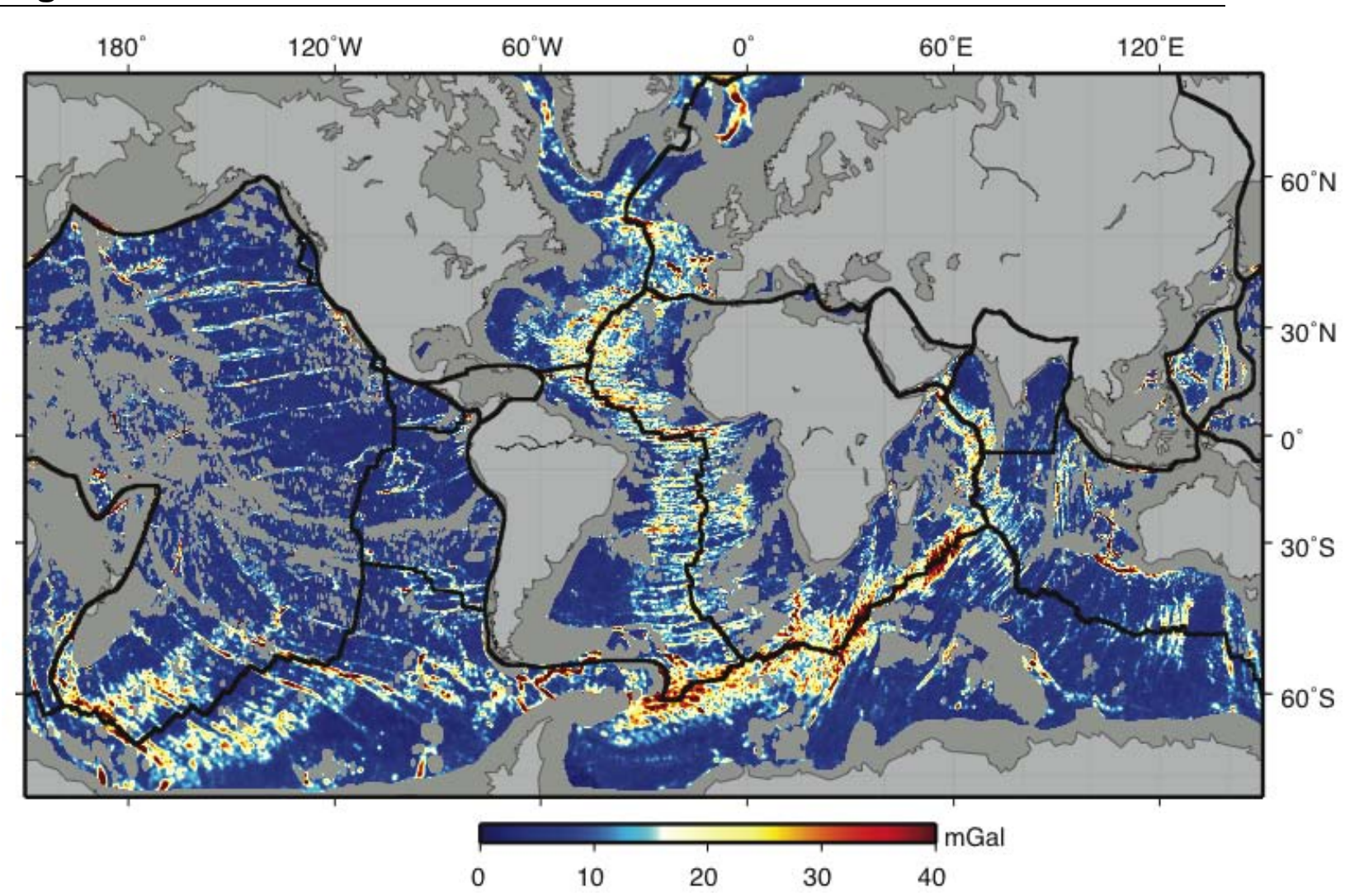

Fig. 1. RMS downward-continued gravity roughness calculated using a Gaussian filter with a half-width of $50 \mathrm{~km}$. Plate boundaries shown as heavy black lines, landmasses in light grey, and masked continental shelves, seamounts and large igneous provinces in dark grey. 

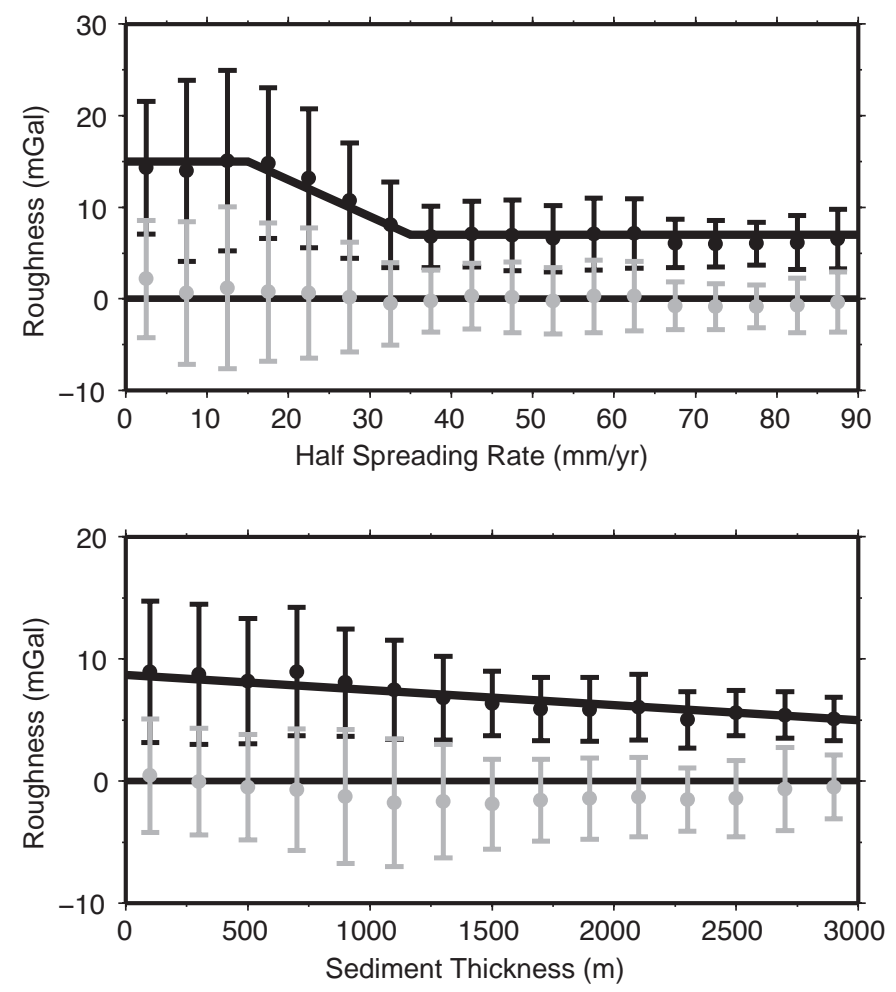
Fig. 2. Gravity roughness as a function of (a) spreading half-rates and (b) sediment thickness. Median roughness and its median absolute deviation were calculated in bins sized $5 \mathrm{~mm} / \mathrm{yr}$ for half-spreading rates and $200 \mathrm{~m}$ for sediment thickness, respectively (black dots). Dark grey lines on each graph shows line of best fit, which is used to remove the effects of spreading rate and sediment thickness from gravity roughness. Light grey dots show variation of residual gravity roughness (see Figure 3), with (a) spreading rate and (b) sediment thickness. Error bars show +/- median absolute deviation (MAD).

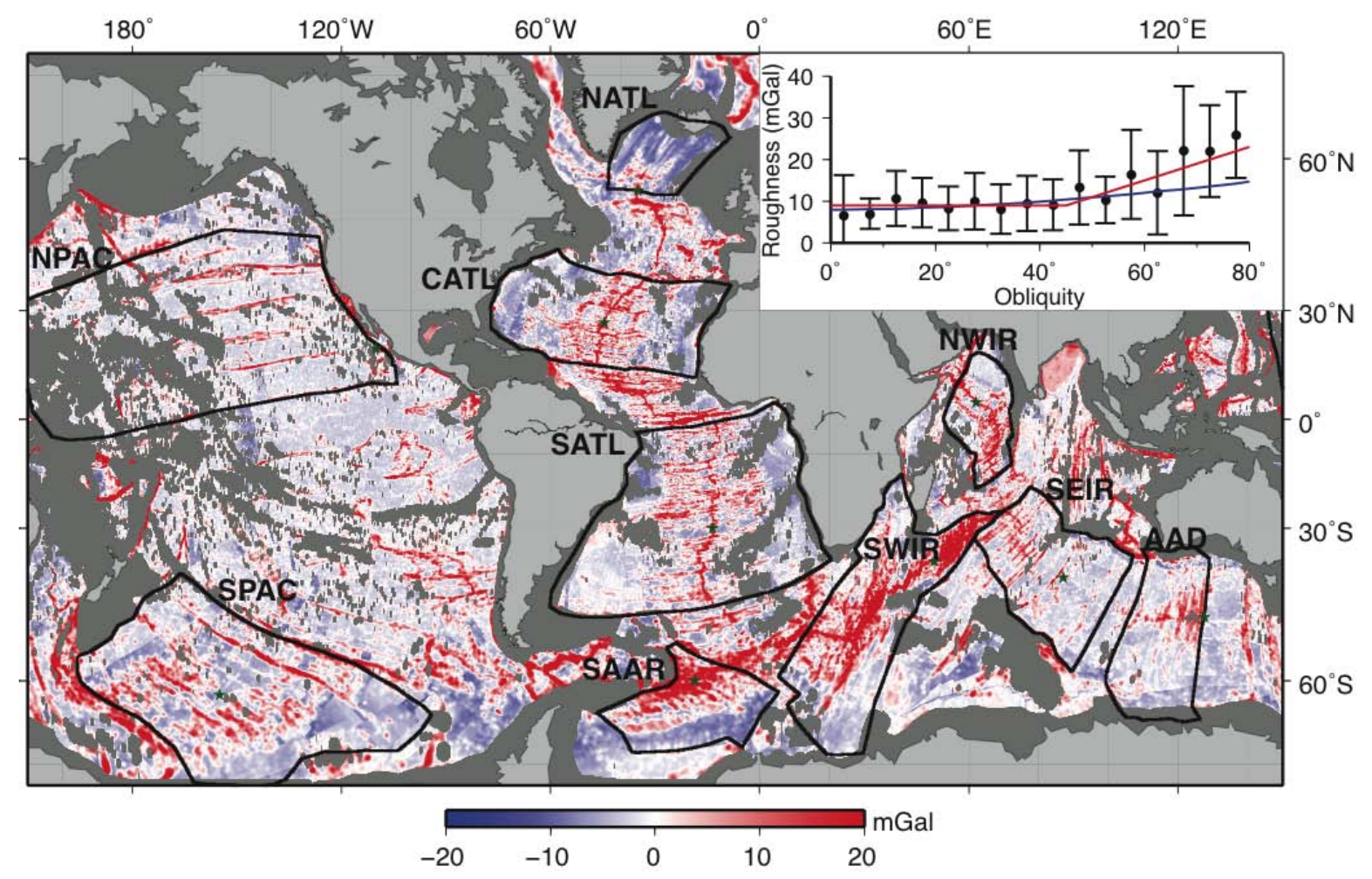

Fig. 3. Residual roughness, after removing effects of spreading rate and sediment thickness from the RMS-roughness grid. Black lines: individual spreading systems. Green stars: locations where spreading direction through time were calculated for each region. Inset graph: relationship between roughness and spreading obliquity, error bars - median absolute deviation. Red line: 2-stage line of best fit. Blue line: basement roughness expected due to the influence of spreading obliquity on spreading rates assuming roughness equals $8 \mathrm{mGal}$ at $0^{\circ}$. NPAC - North Pacific; SPAC - South Pacific; NATL - North Atlantic; CATL - Central Atlantic; SATL - South Atlantic; SAAR South American-Antarctic Ridge; SWIR - Southwest Indian Ridge; NWIR - Northwest Indian Ridge; SEIR - Southeast Indian Ridge; AAD - Australian-Antarctic Discordance.

Fig. 4. Variation of residual roughness in 5 million year stages for ten selected regions. Grey line with black dots shows residual roughness for regions (a) NWIR, (b) NATL, (c) SEIR, (d) CATL, (e) AAD, (f) SATL, (g) NPAC, (h) SAAR, (i) SPAC, and (j) SWIR. Grey envelope shows the $+/$ - median absolute deviation (MAD). Black line with grey dots shows residual roughness with roughness attributable to spreading obliquity removed using the relationship shown by the red line in Fig. 3 (inset). 

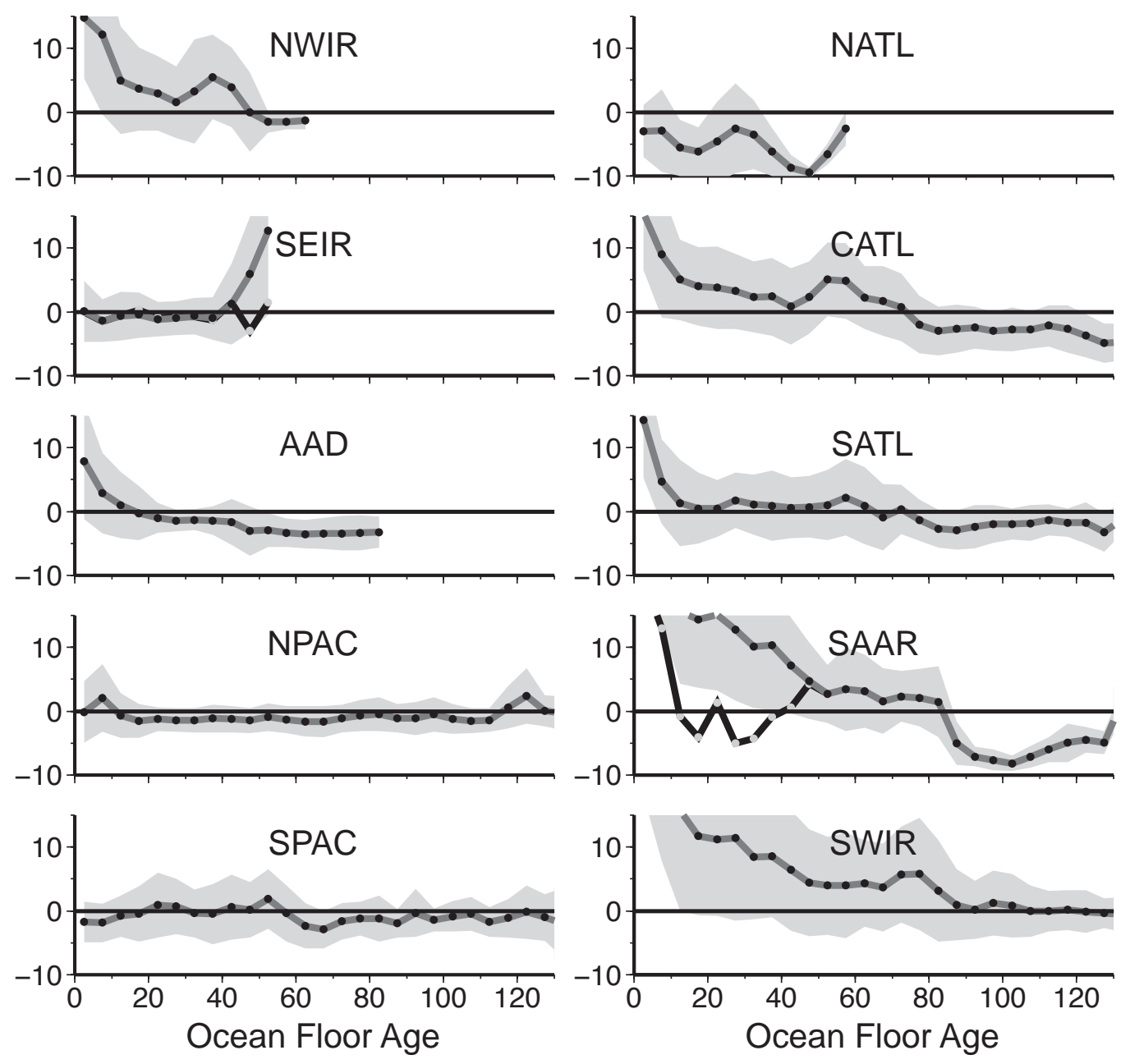

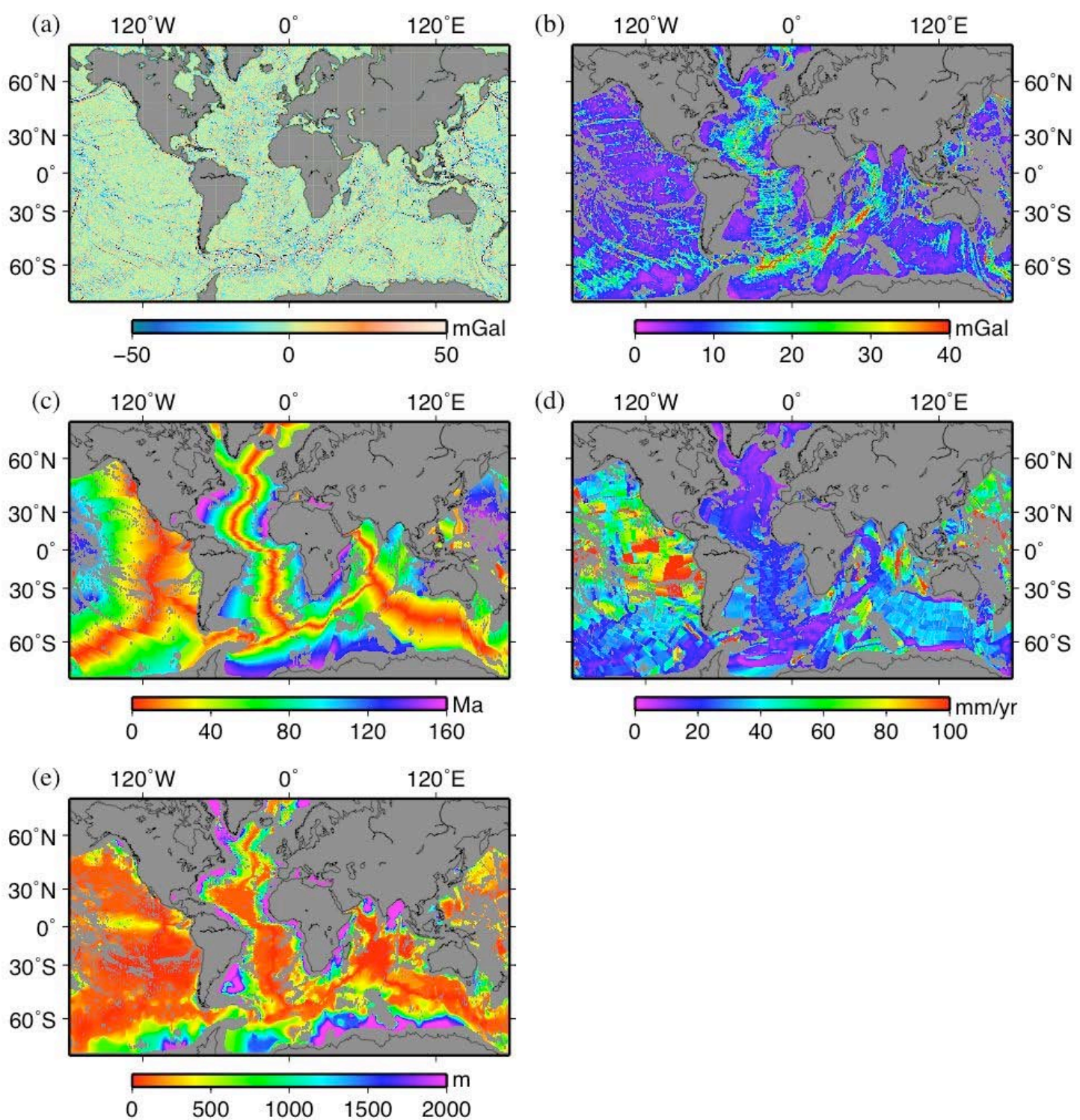

Supplementary Figure 1: Global marine 2-minute grids of (a) downward-continued marine gravity anomalies, (b) masked RMS-gravity roughness, (c) oceanic crustal age, (d) half-spreading rates, and (e) sediment thickness. 


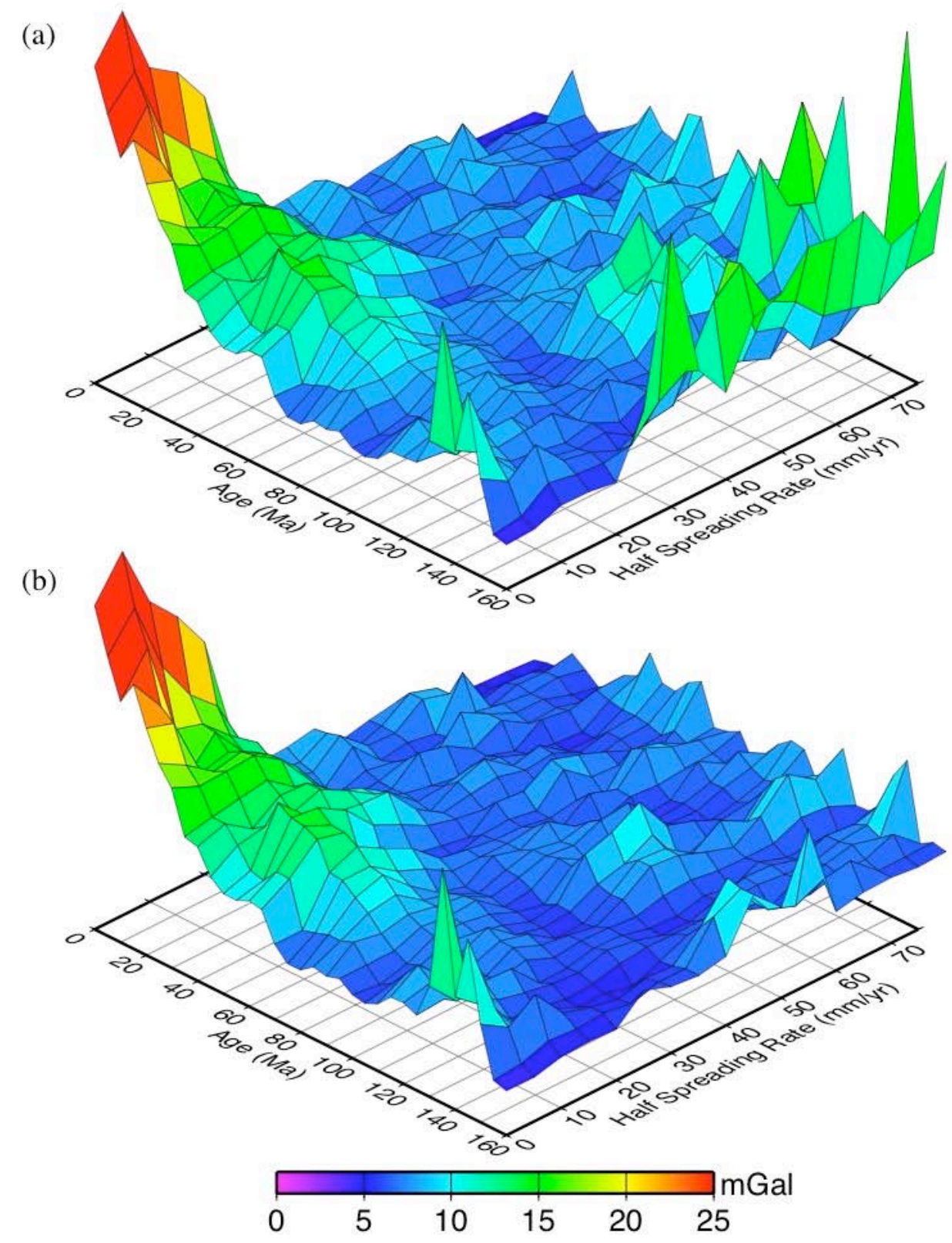

Supplementary Figure 2: (a) Unmasked, and (b) masked, gravity roughness as a function of crustal age and spreading half-rates, obtained by calculating the median roughness and its median absolute deviation in bins sized $5 \mathrm{~m}$.y for crustal age, and 5 $\mathrm{mm} / \mathrm{yr}$ for half-spreading rates. 


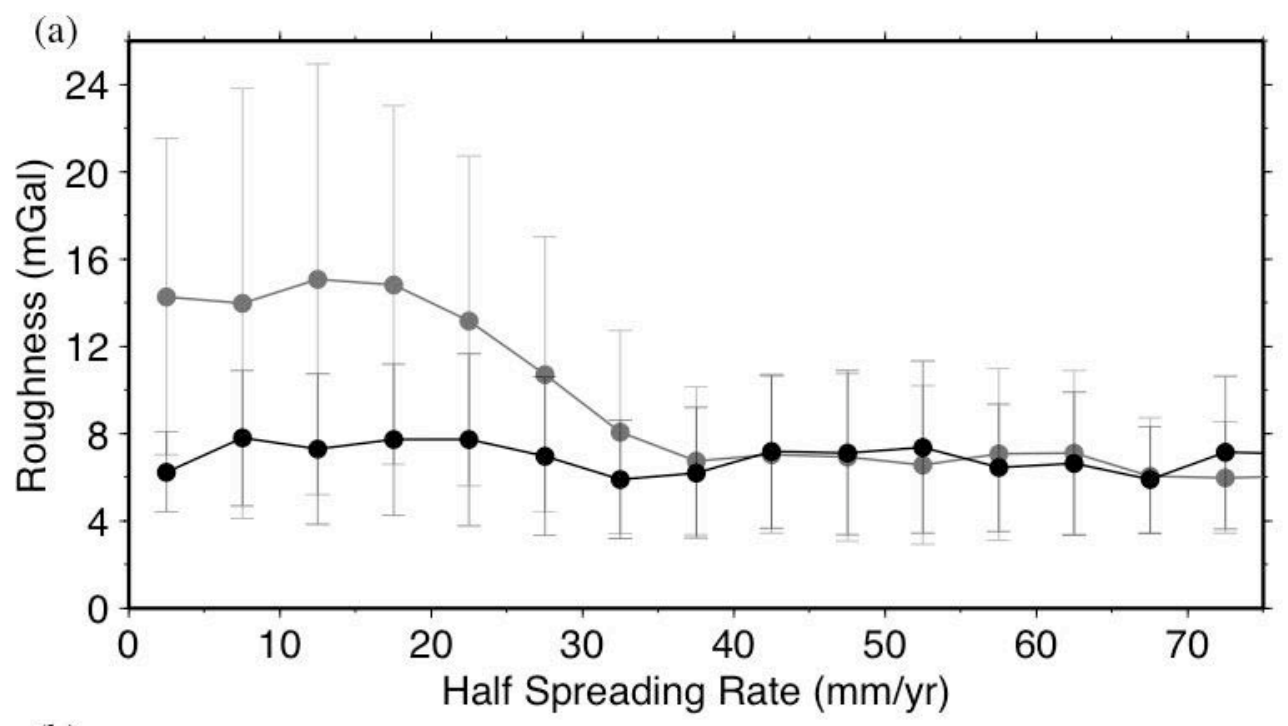

(b)

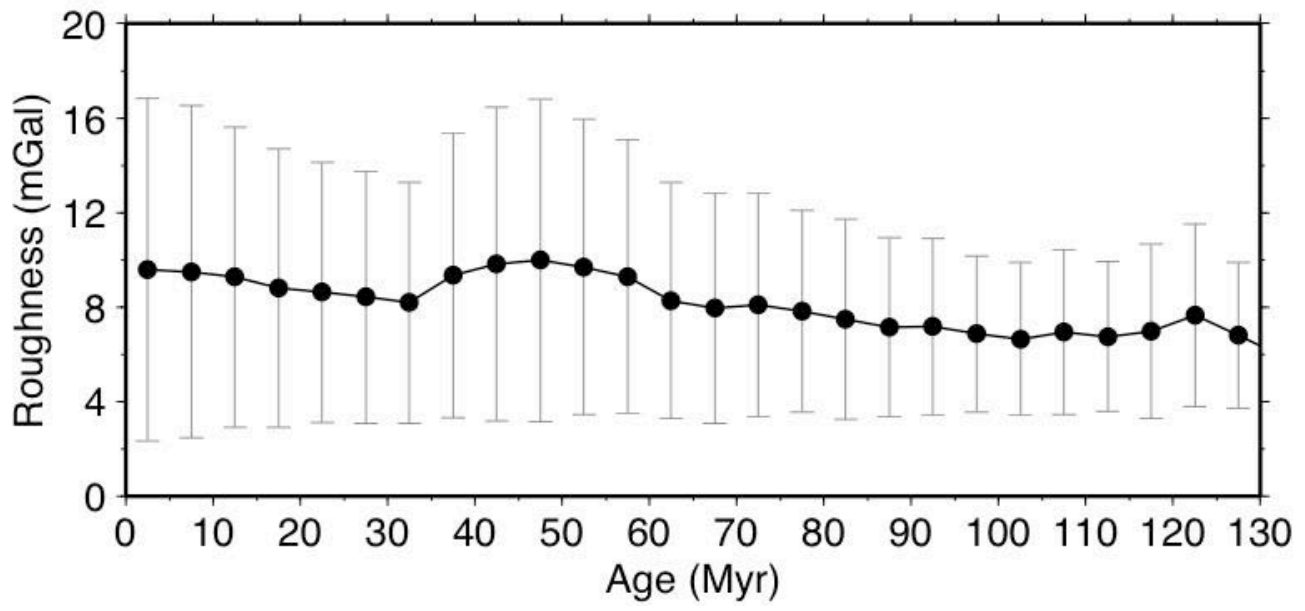

Supplementary Figure 3: Gravity roughness as a function of (a) half-spreading rate, for global crust aged 0-80 Myr (grey) and 80-130 Myr (black), and (b) crustal age. Note that basement roughness increases with slowing spreading rates for crust $0-80$ Ma, but the same relationship does not exist for crust aged 80-130 Myr. However, no significant variation of roughness occurs with crustal age across all spreading rates. We suggest that most crust aged between 80 and 130 Myr exhibits relatively smooth basement irrespective of spreading rates due to underlying hot supercontinent-derived mantle. 
(a)

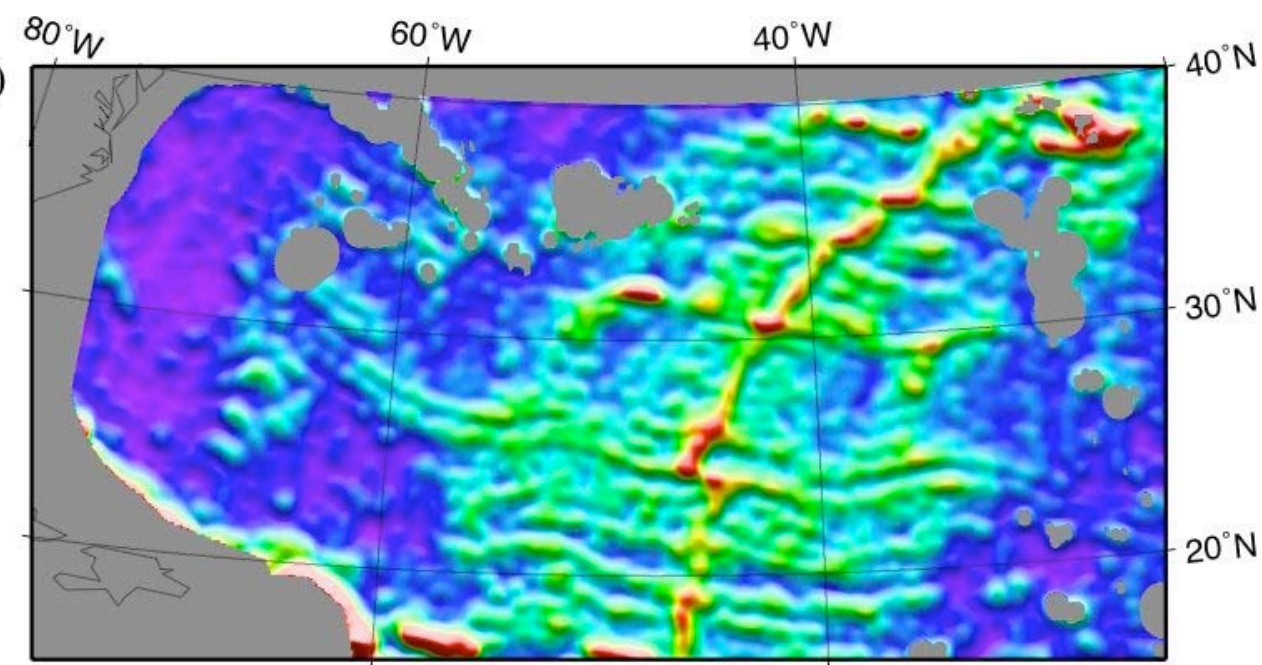

(b)

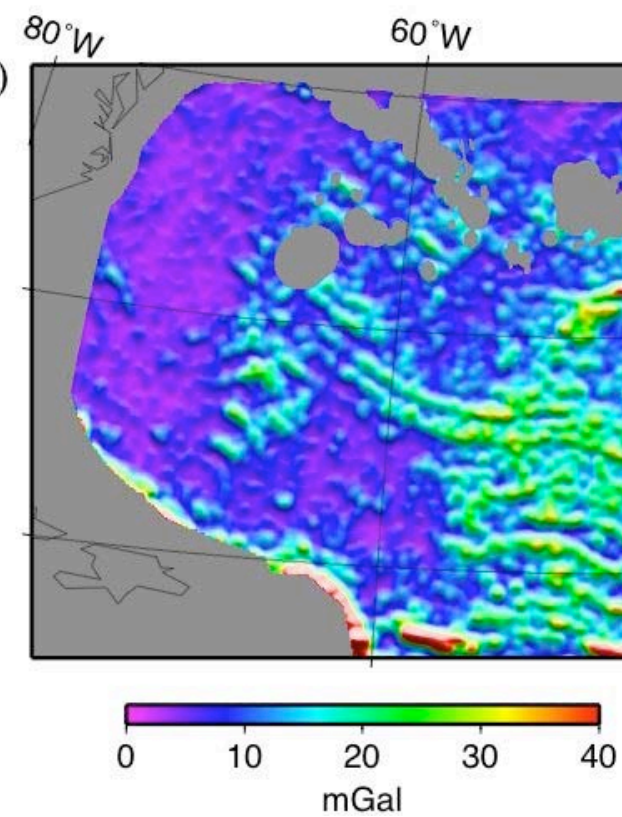

Supplementary Figure 4: Lambert equal area maps of gravity roughness calculated using a Gaussian filter of (a) $160 \mathrm{~km}$, and (b) $100 \mathrm{~km}$. 


\section{(a)}

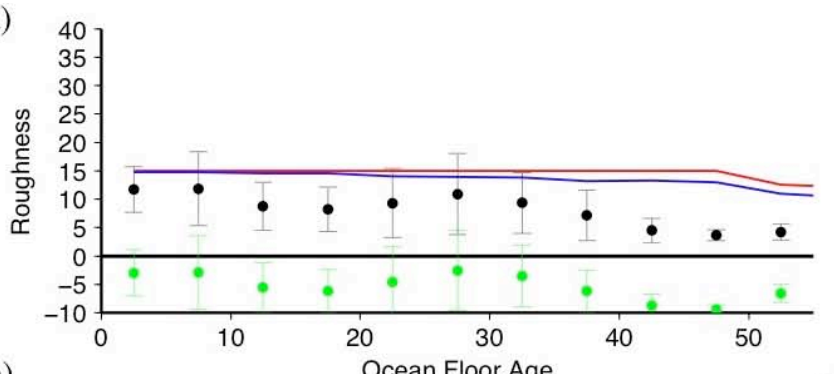

(b)

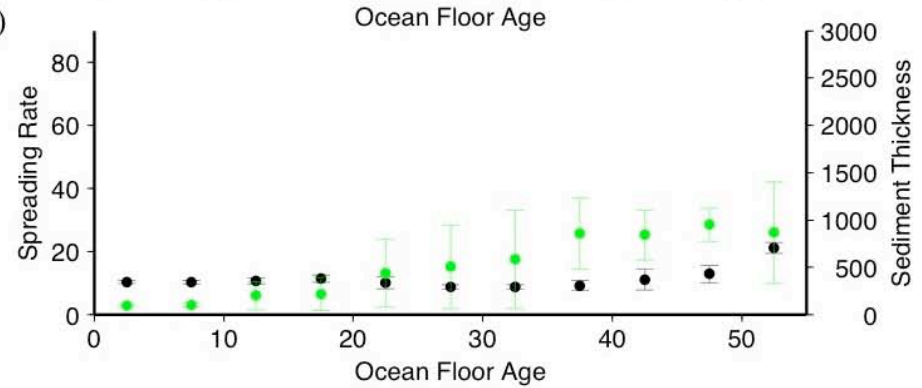

(c)

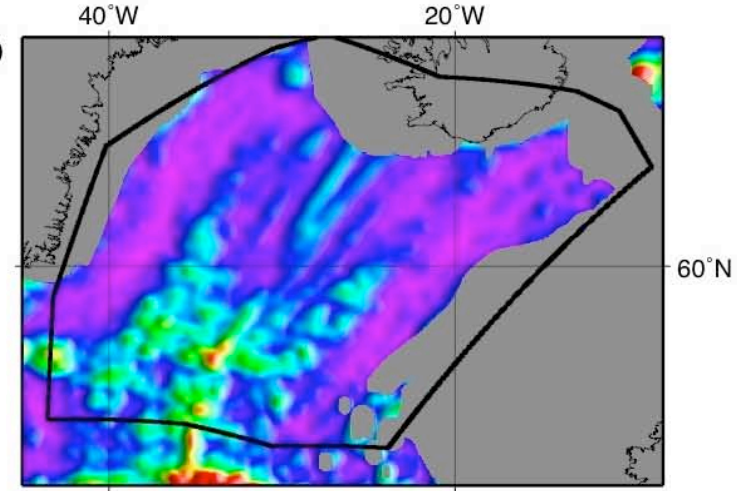

(d)
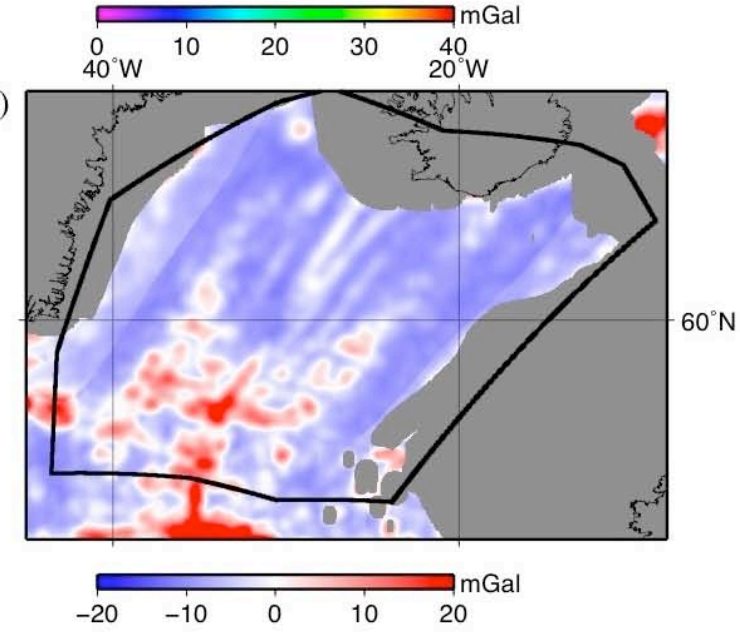

Supplementary Figure 5: North Atlantic (a) gravity roughness (black dots) and residual gravity roughness (green dots) as a function of age. Predicted gravity roughness using spreading rates only (red line) and using both spreading rates and sediment thickness (blue line), (b) spreading rate (black dots) and sediment thickness (green dots) as a function of age. Roughness, residual roughness, spreading rate and sediment thickness values obtained by calculating the median and median absolute deviation in bins sized $5 \mathrm{Myr}$, (c) gravity roughness, and (d) residual gravity roughness. The residual roughness grid is computed using the gravity roughness grid, sediment thickness grid, and the spreading rate grid, which is based on constant spreading rates between isochrons. 
(a)

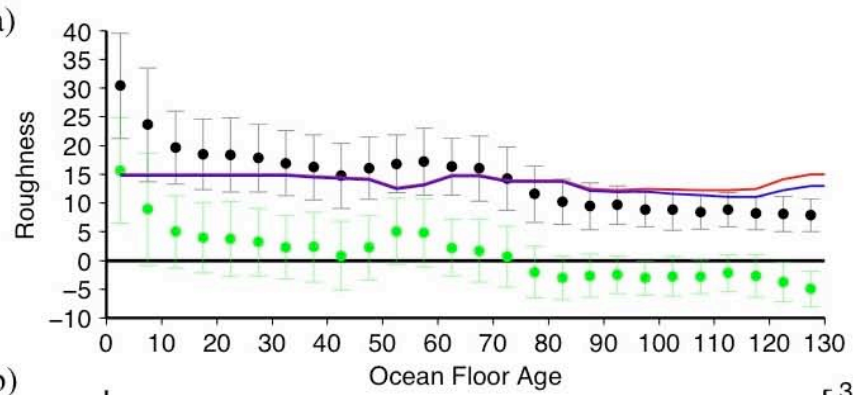

(b)
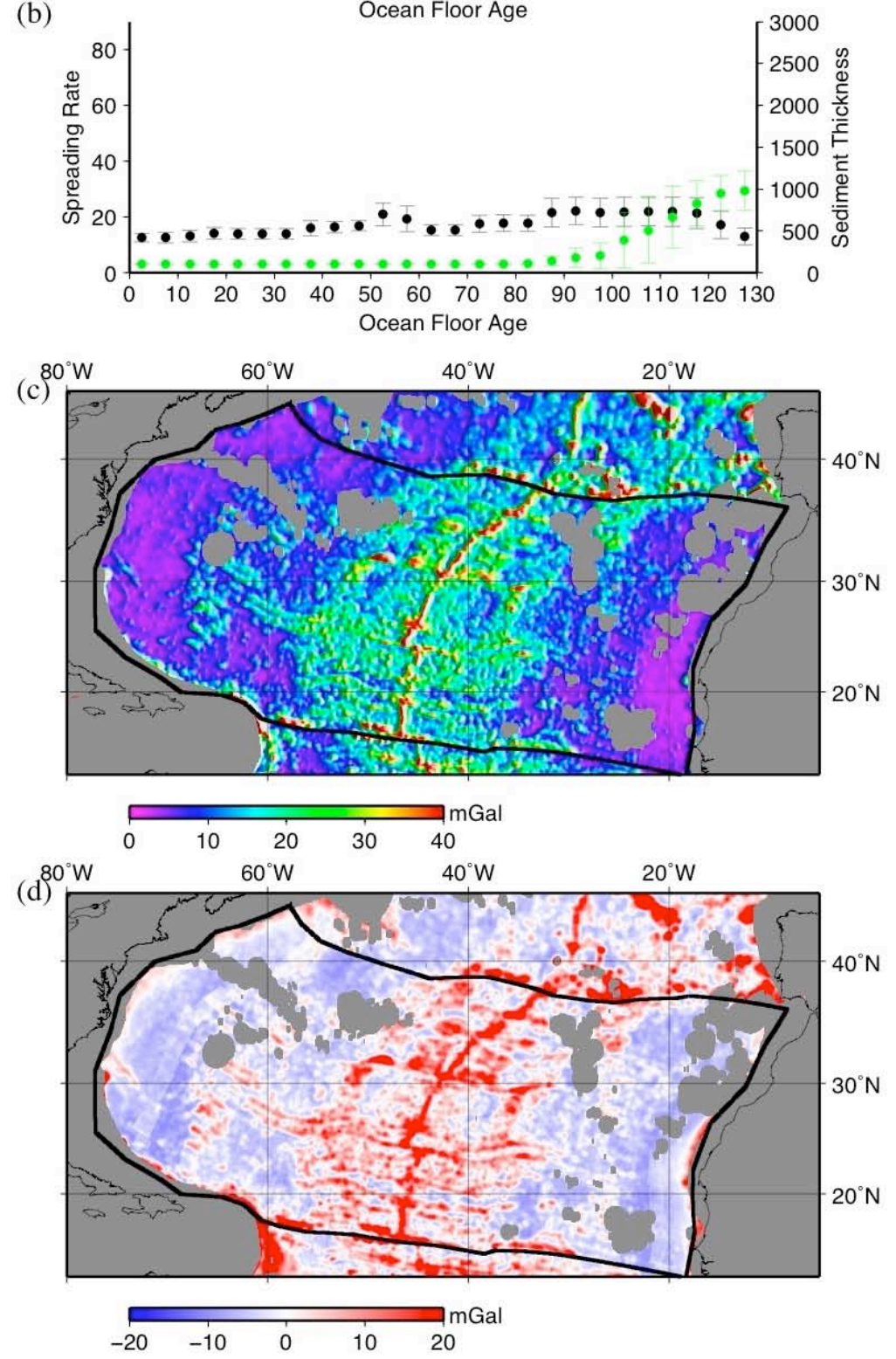

Supplementary Figure 6: Central Atlantic (a) gravity roughness (black dots) and residual gravity roughness (green dots) as a function of age. Predicted gravity roughness using spreading rates only (red line) and using both spreading rates and sediment thickness (blue line), (b) spreading rate (black dots) and sediment thickness (green dots) as a function of age. Roughness, residual roughness, spreading rate and sediment thickness values obtained by calculating the median and median absolute deviation in bins sized $5 \mathrm{Myr}$, (c) gravity roughness, and (d) residual gravity roughness. The residual roughness grid is computed using the gravity roughness grid, sediment thickness grid, and the spreading rate grid, which is based on constant spreading between isochrons. 
(a)

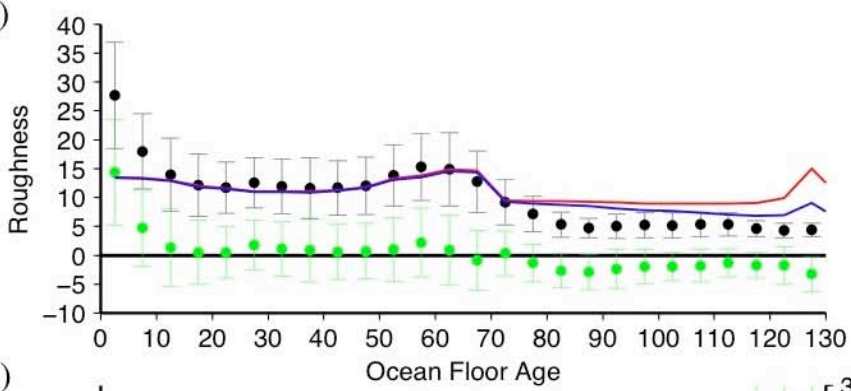

(b)

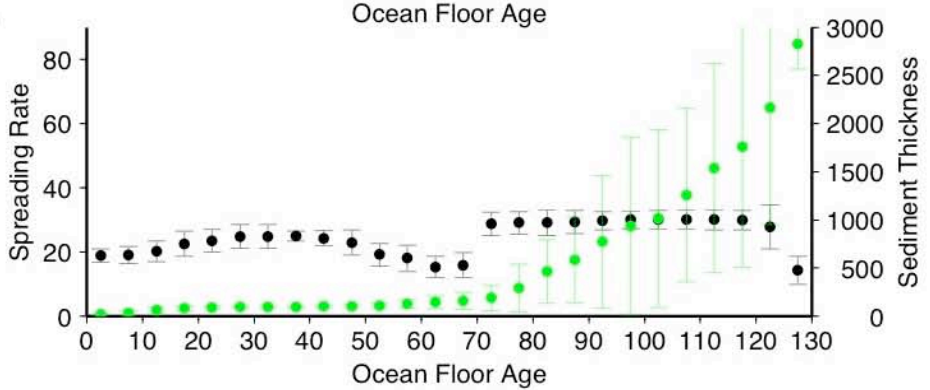

(c)

$\begin{array}{lllll}60^{\circ} \mathrm{W} & 40^{\circ} \mathrm{W} & 20^{\circ} \mathrm{W} & 0^{\circ} & 20^{\circ} \mathrm{E}\end{array}$
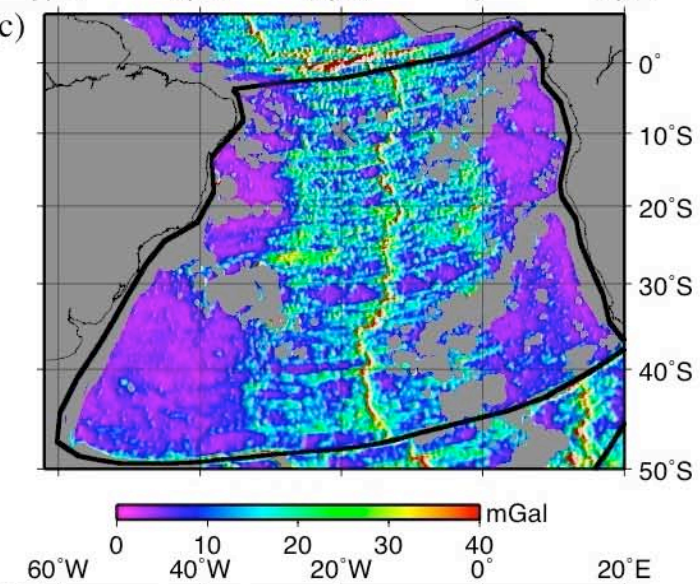

(d)

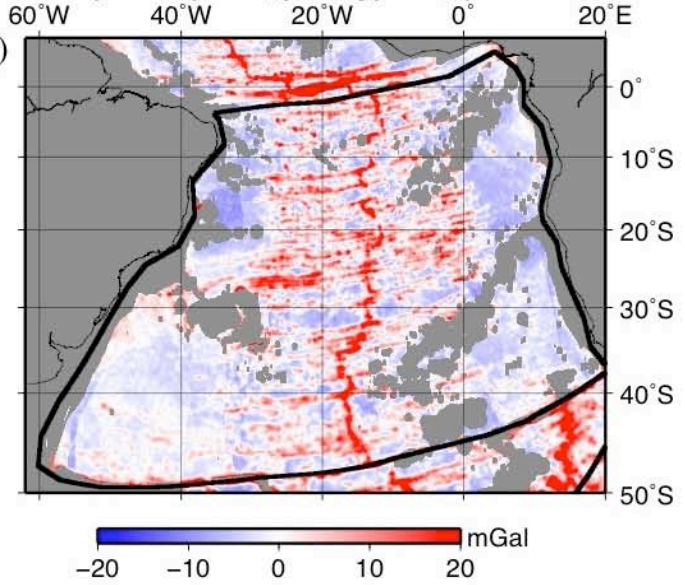

Supplementary Figure 7: South Atlantic (a) gravity roughness (black dots) and residual gravity roughness (green dots) as a function of age. Predicted gravity roughness using spreading rates only (red line) and using both spreading rates and sediment thickness (blue line), (b) spreading rate (black dots) and sediment thickness (green dots) as a function of age. Roughness, residual roughness, spreading rate and sediment thickness values obtained by calculating the median and median absolute deviation in bins sized $5 \mathrm{Myr}$, (c) gravity roughness, and (d) residual gravity roughness. The residual roughness grid is computed using the gravity roughness grid, sediment thickness grid, and the spreading rate grid, which is based on constant spreading between isochrons. 
(a)

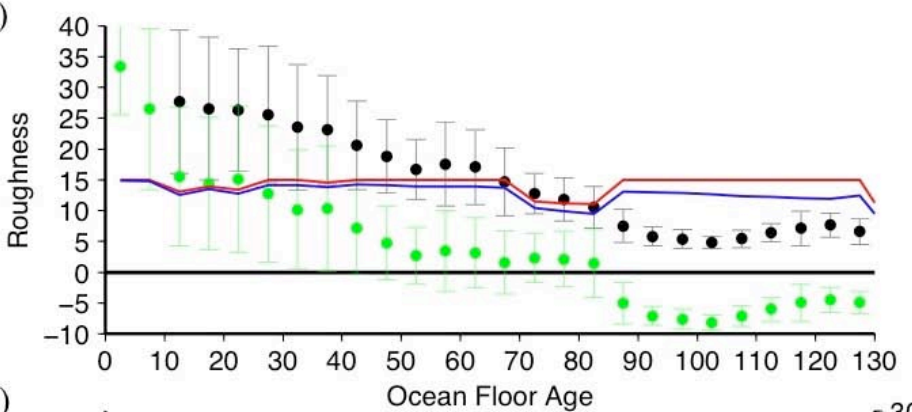

(b)

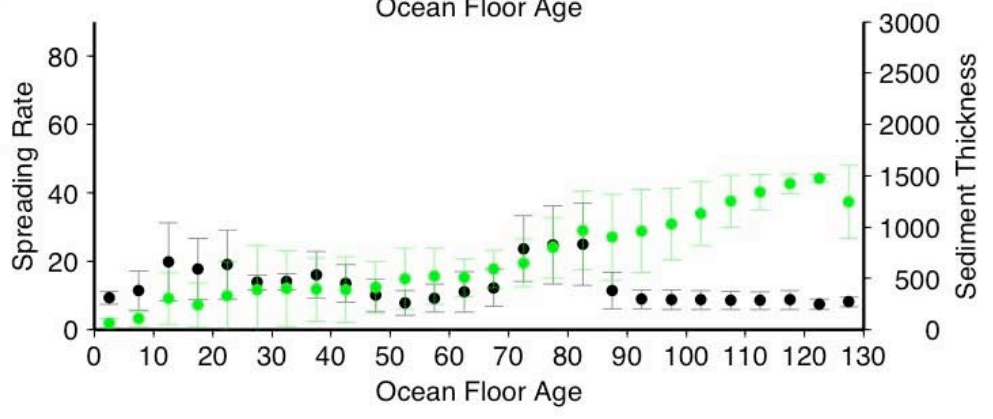

(c)

(d)
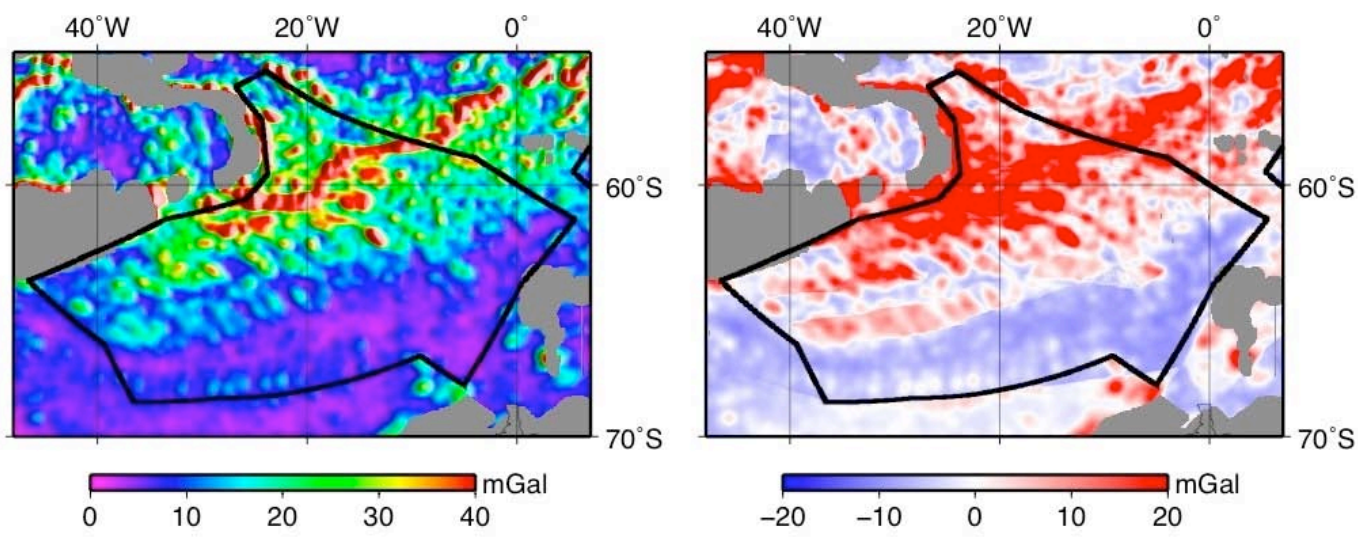

Supplementary Figure 8: South American-Antarctic Ridge (a) gravity roughness (black dots) and residual gravity roughness (green dots) as a function of age. Predicted gravity roughness using spreading rates only (red line) and using both spreading rates and sediment thickness (blue line), (b) spreading rate (black dots) and sediment thickness (green dots) as a function of age. Roughness, residual roughness, spreading rate and sediment thickness values obtained by calculating the median and median absolute deviation in bins sized $5 \mathrm{Myr}$, (c) gravity roughness, and (d) residual gravity roughness. The residual roughness grid is computed using the gravity roughness grid, sediment thickness grid, and the spreading rate grid, which is based on constant spreading between isochrons. 


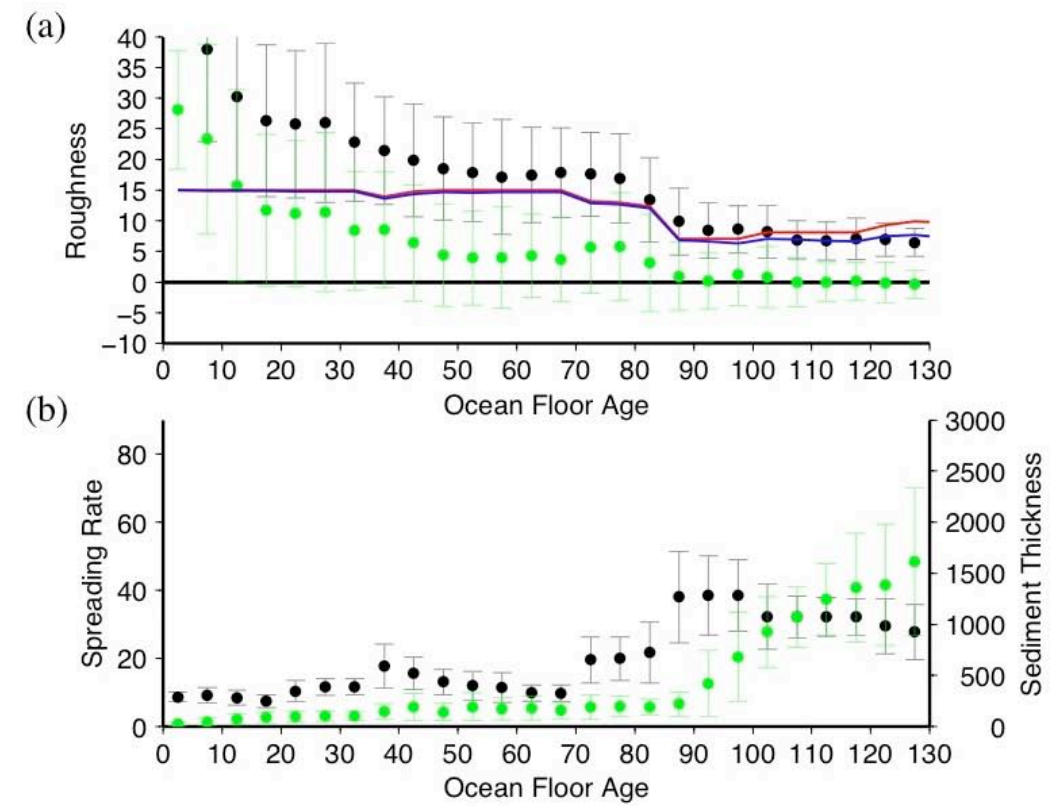

(c)

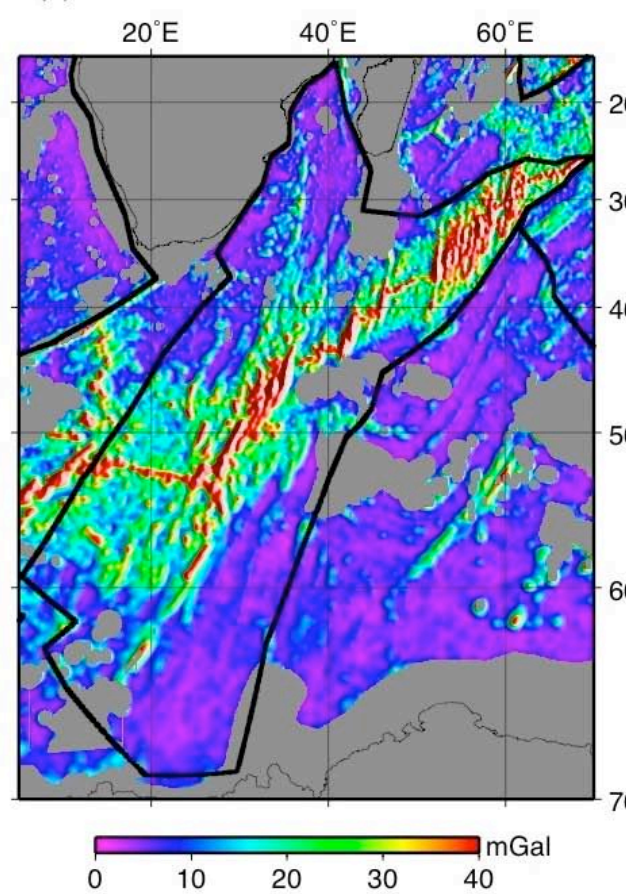

(d)

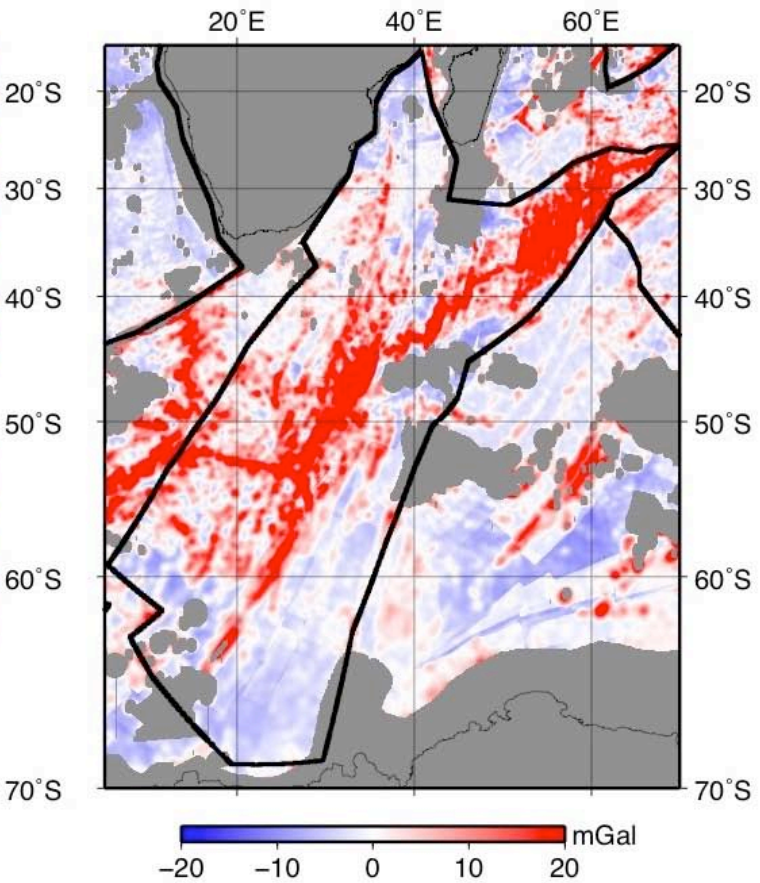

Supplementary Figure 9: Southwest Indian Ridge (a) gravity roughness (black dots) and residual gravity roughness (green dots) as a function of age. Predicted gravity roughness using spreading rates only (red line) and using both spreading rates and sediment thickness (blue line), (b) spreading rate (black dots) and sediment thickness (green dots) as a function of age. Roughness, residual roughness, spreading rate and sediment thickness values obtained by calculating the median and median absolute deviation in bins sized $5 \mathrm{Myr}$, (c) gravity roughness, and (d) residual gravity roughness. The residual roughness grid is computed using the gravity roughness grid, sediment thickness grid, and the spreading rate grid, which is based on constant spreading between isochrons. 
(a)

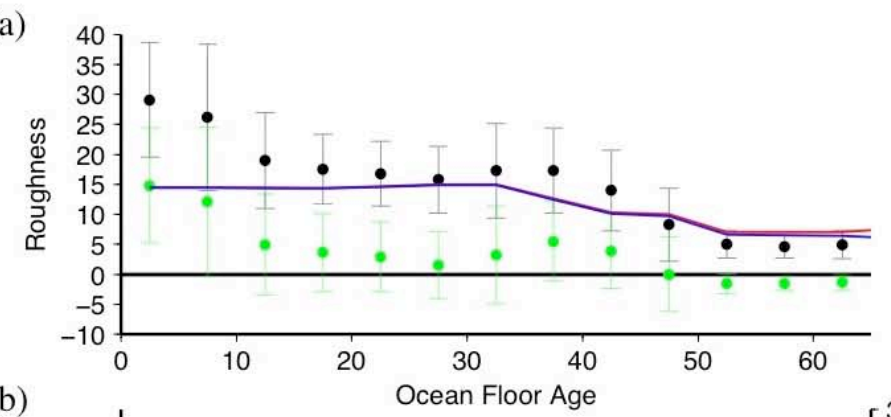

(b)

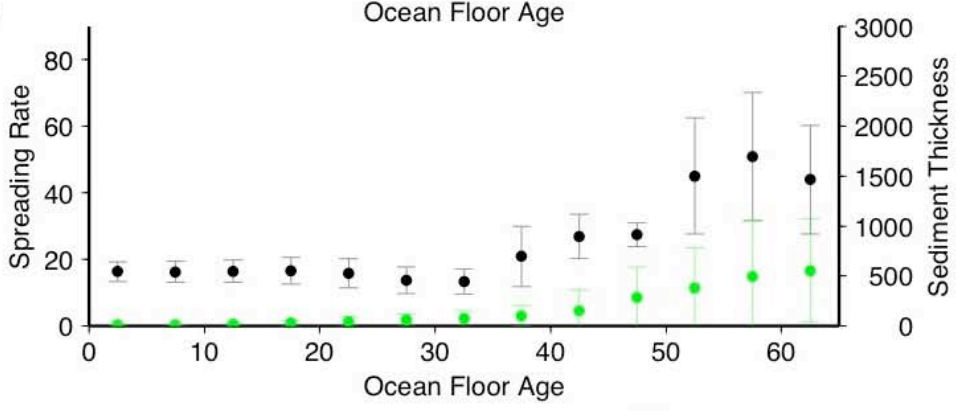

(c)

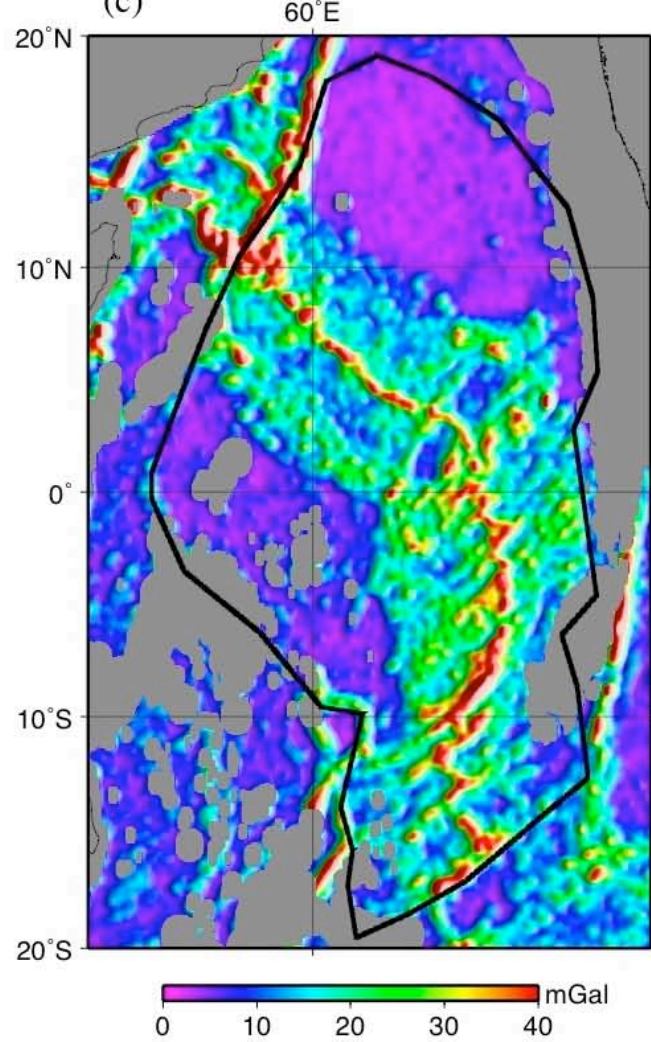

(d)

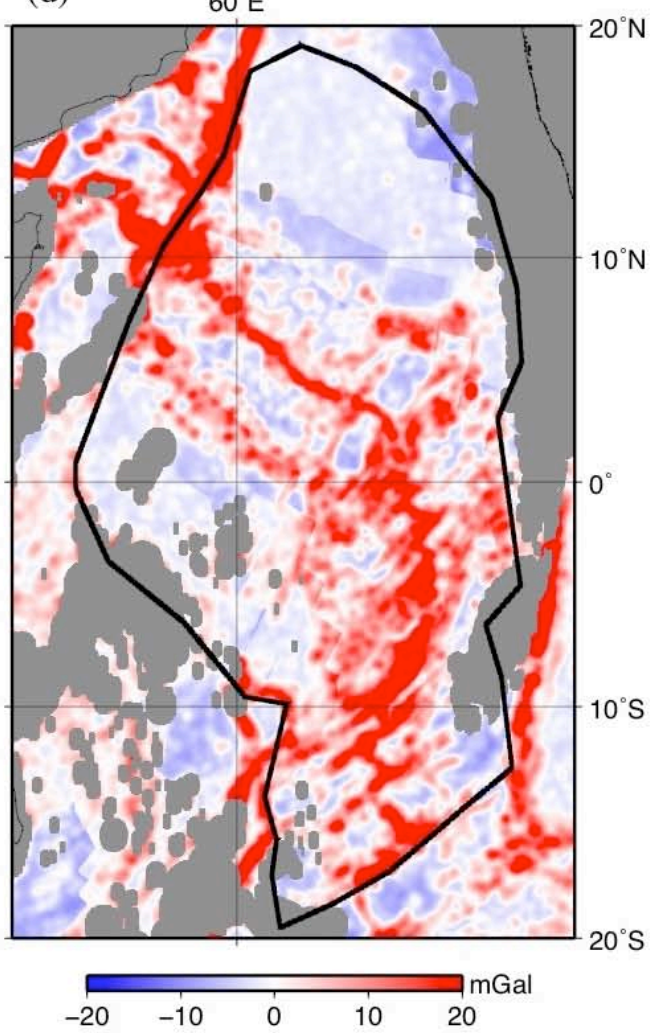

Supplementary Figure 10: Northwest Indian Ridge ((a) gravity roughness (black dots) and residual gravity roughness (green dots) as a function of age. Predicted gravity roughness using spreading rates only (red line) and using both spreading rates and sediment thickness (blue line), (b) spreading rate (black dots) and sediment thickness (green dots) as a function of age. Roughness, residual roughness, spreading rate and sediment thickness values obtained by calculating the median and median absolute deviation in bins sized $5 \mathrm{Myr}$, (c) gravity roughness, and (d) residual gravity roughness. The residual roughness grid is computed using the gravity roughness grid, sediment thickness grid, and the spreading rate grid, which is based on constant spreading between isochrons. 
(a)

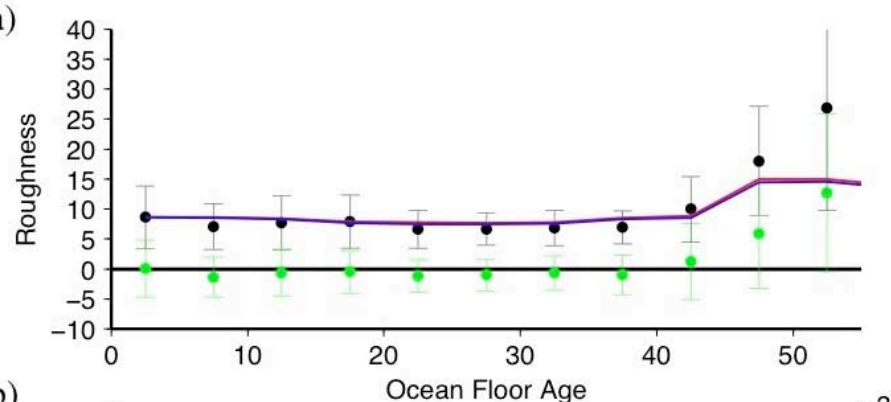

(b)

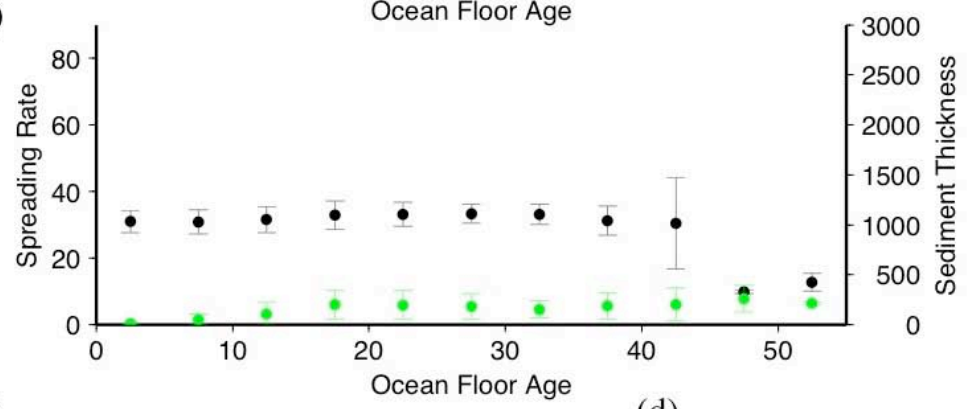

(c)
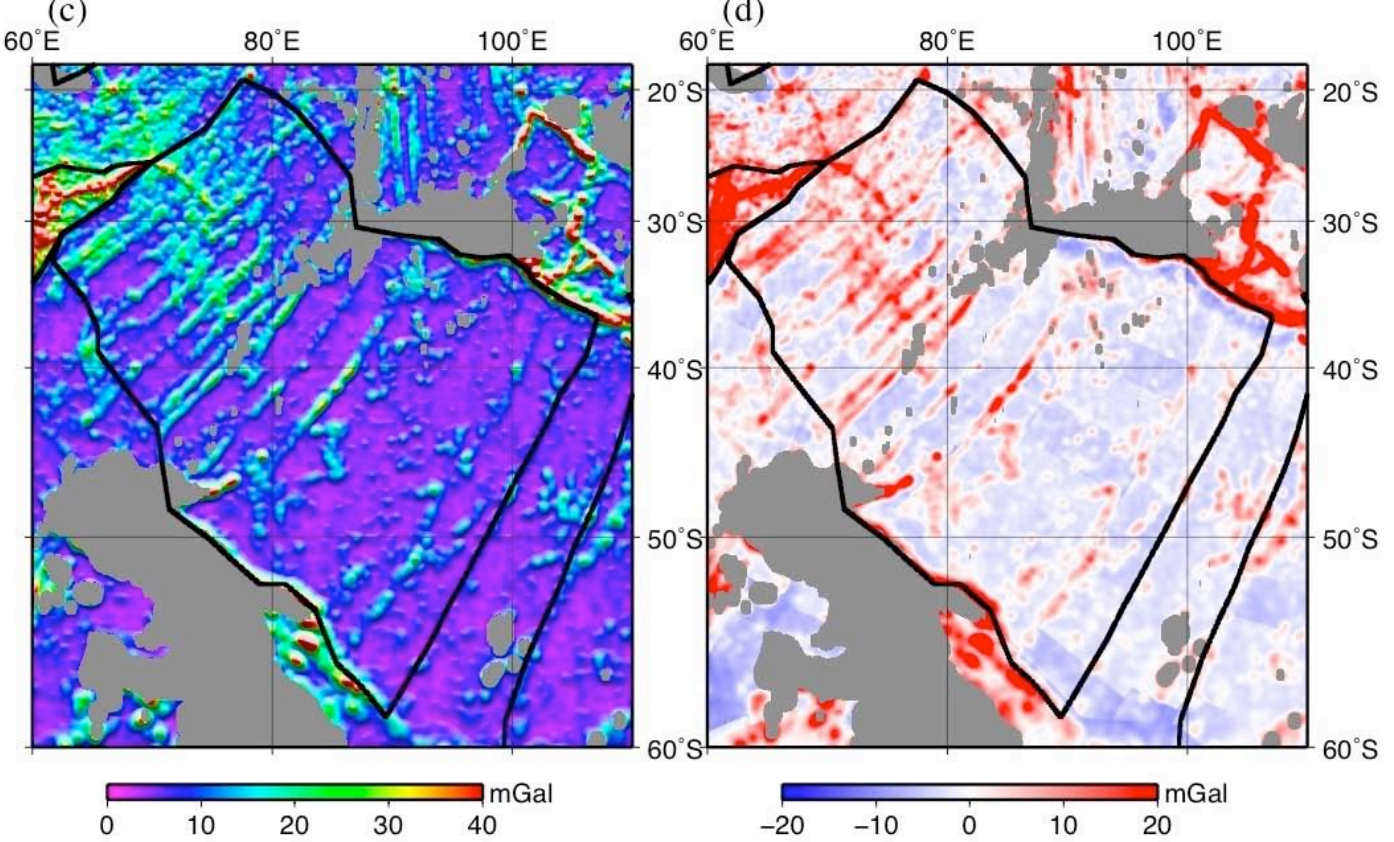

Supplementary Figure 11: Southeast Indian Ridge (a) gravity roughness (black dots) and residual gravity roughness (green dots) as a function of age. Predicted gravity roughness using spreading rates only (red line) and using both spreading rates and sediment thickness (blue line), (b) spreading rate (black dots) and sediment thickness (green dots) as a function of age. Roughness, residual roughness, spreading rate and sediment thickness values obtained by calculating the median and median absolute deviation in bins sized $5 \mathrm{Myr}$, (c) gravity roughness, and (d) residual gravity roughness. The residual roughness grid is computed using the gravity roughness grid, sediment thickness grid, and the spreading rate grid, which is based on constant spreading between isochrons. 


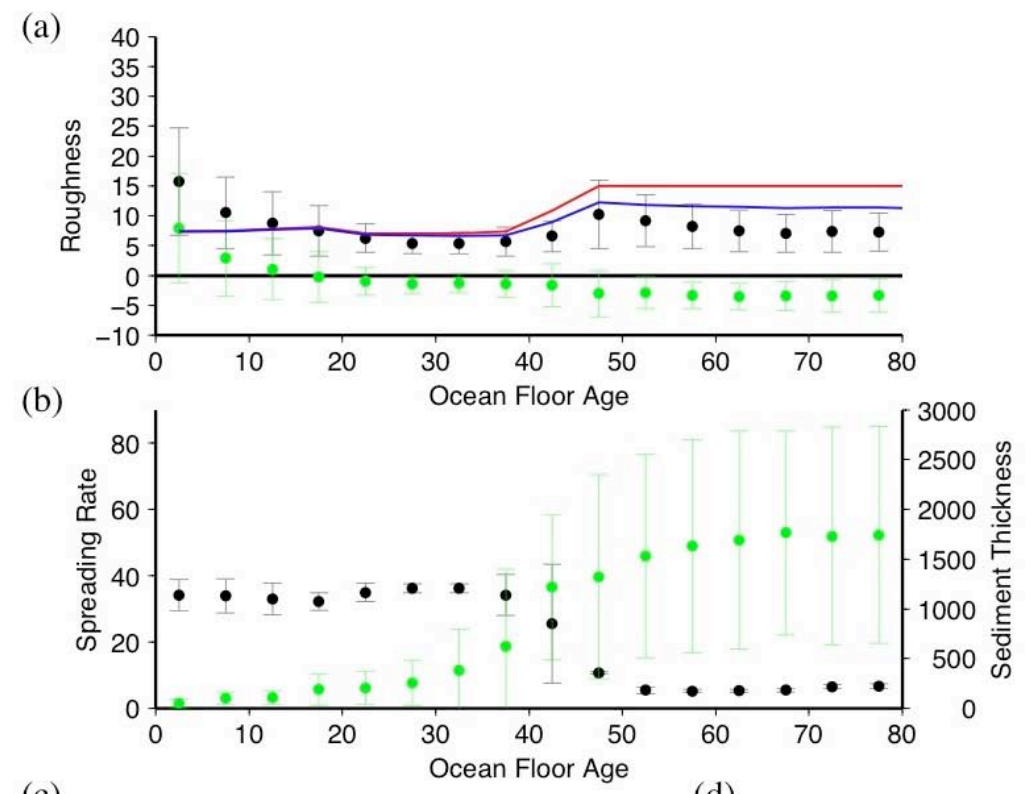

(c)

(d)
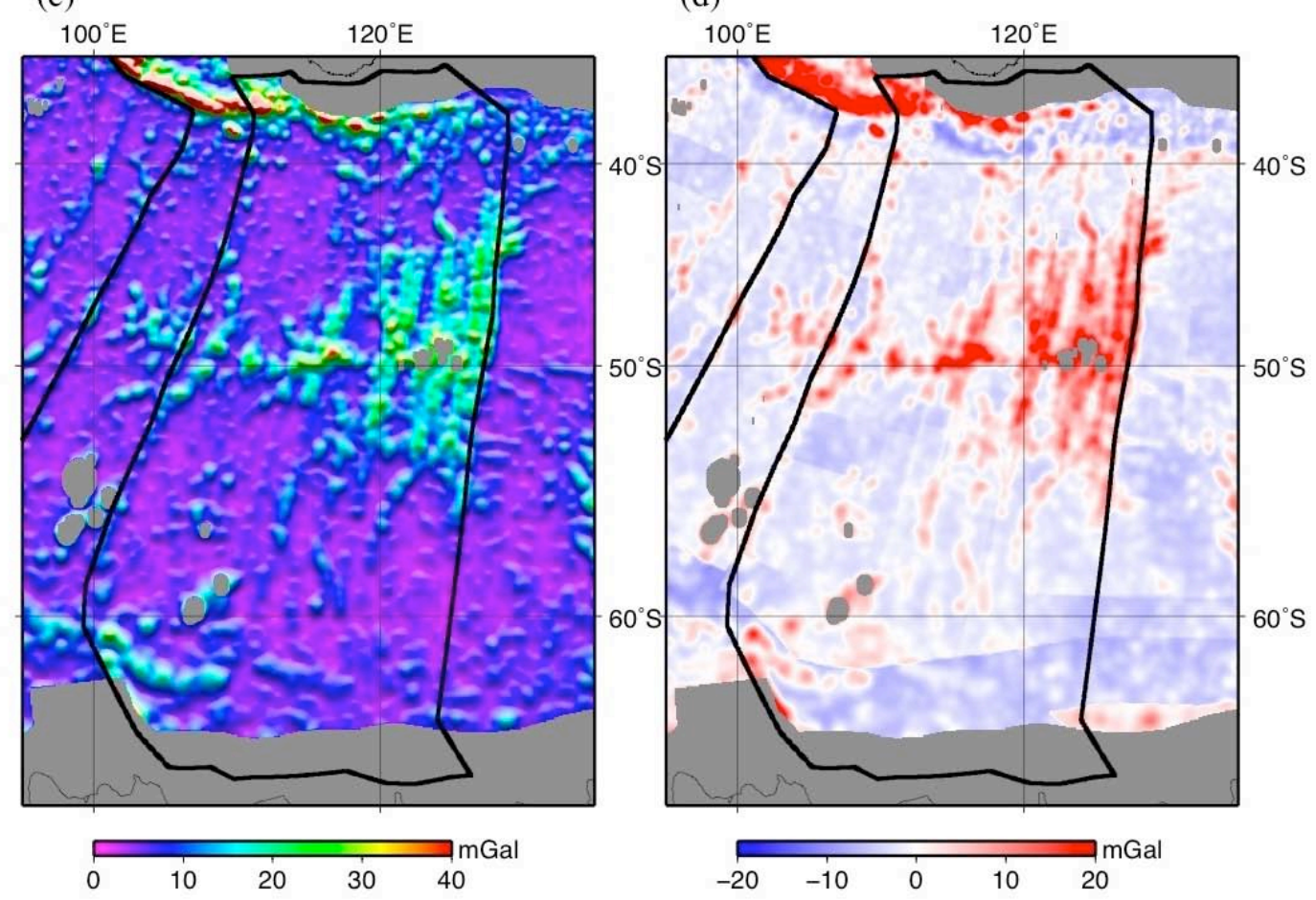

Supplementary Figure 12: Australian-Antarctic Discordance (a) gravity roughness (black dots) and residual gravity roughness (green dots) as a function of age. Predicted gravity roughness using spreading rates only (red line) and using both spreading rates and sediment thickness (blue line), (b) spreading rate (black dots) and sediment thickness (green dots) as a function of age. Roughness, residual roughness, spreading rate and sediment thickness values obtained by calculating the median and median absolute deviation in bins sized $5 \mathrm{Myr}$, (c) gravity roughness, and (d) residual gravity roughness. The residual roughness grid is computed using the gravity roughness grid, sediment thickness grid, and the spreading rate grid, which is based on constant spreading between isochrons. 


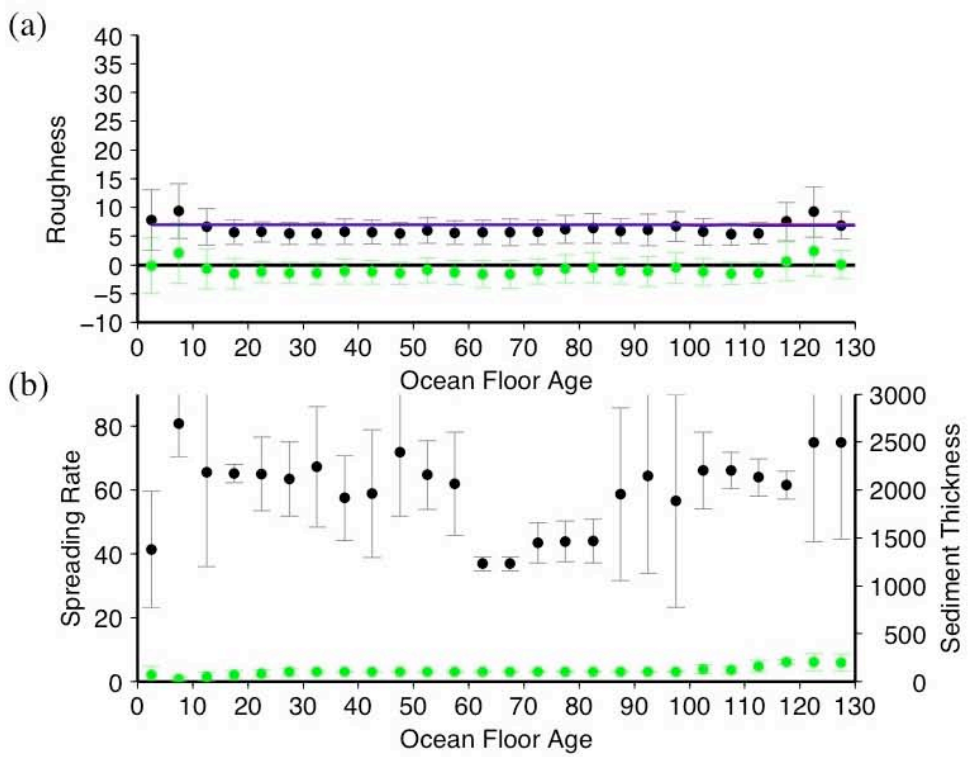

(c)
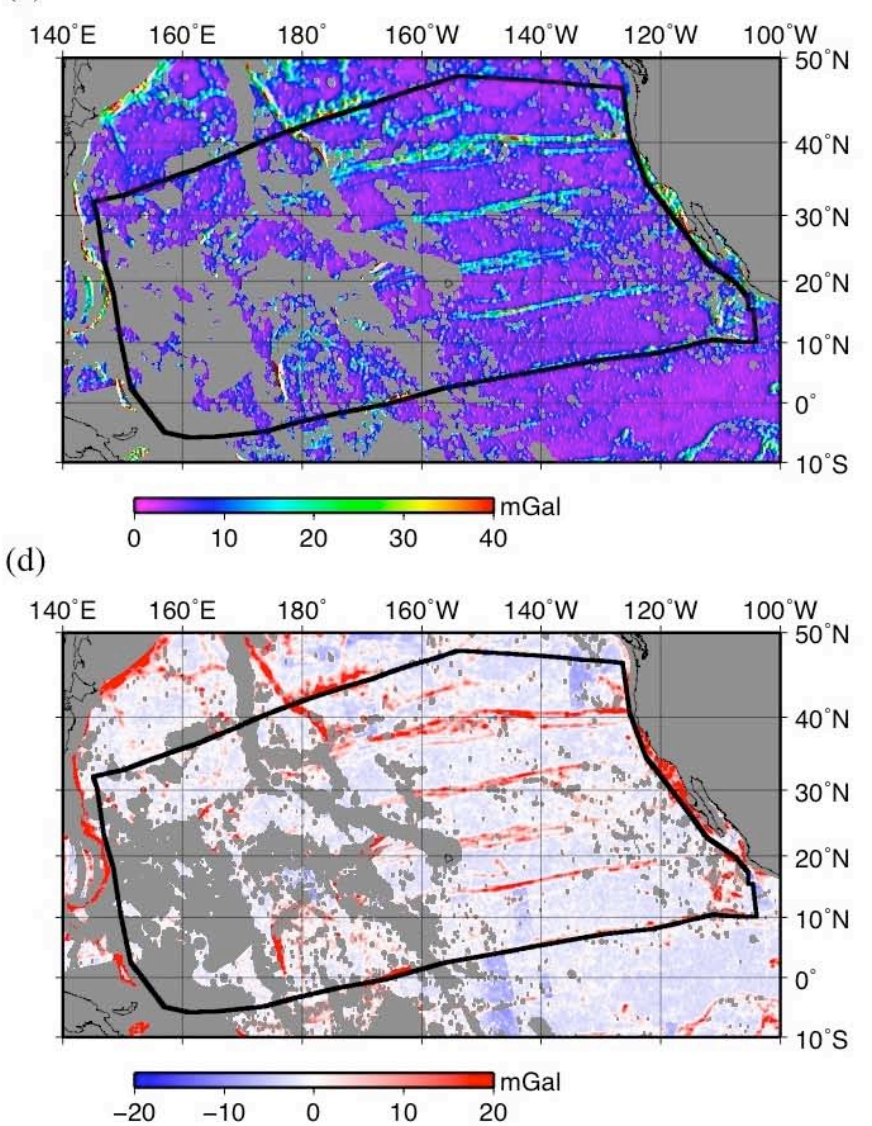

Supplementary Figure 13: North Pacific (a) gravity roughness (black dots) and residual gravity roughness (green dots) as a function of age. Predicted gravity roughness using spreading rates only (red line) and using both spreading rates and sediment thickness (blue line), (b) spreading rate (black dots) and sediment thickness (green dots) as a function of age. Roughness, residual roughness, spreading rate and sediment thickness values obtained by calculating the median and median absolute deviation in bins sized $5 \mathrm{Myr}$, (c) gravity roughness, and (d) residual gravity roughness. The residual roughness grid is computed using the gravity roughness grid, sediment thickness grid, and the spreading rate grid, which is based on constant spreading between isochrons. 


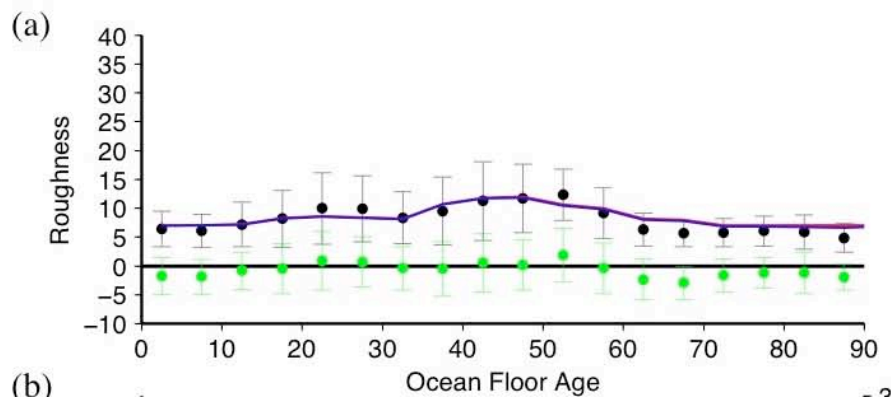

(b)

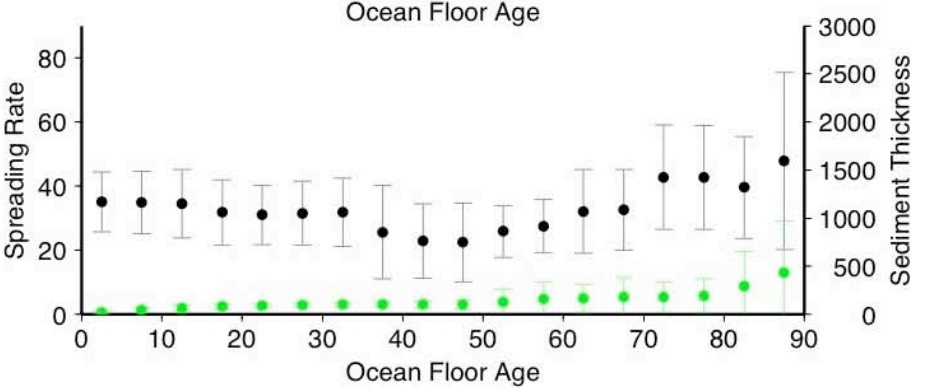

(c)

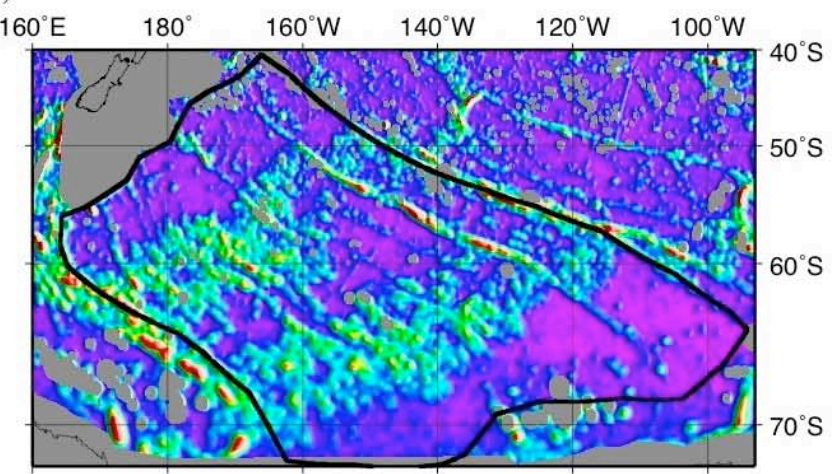

(d)
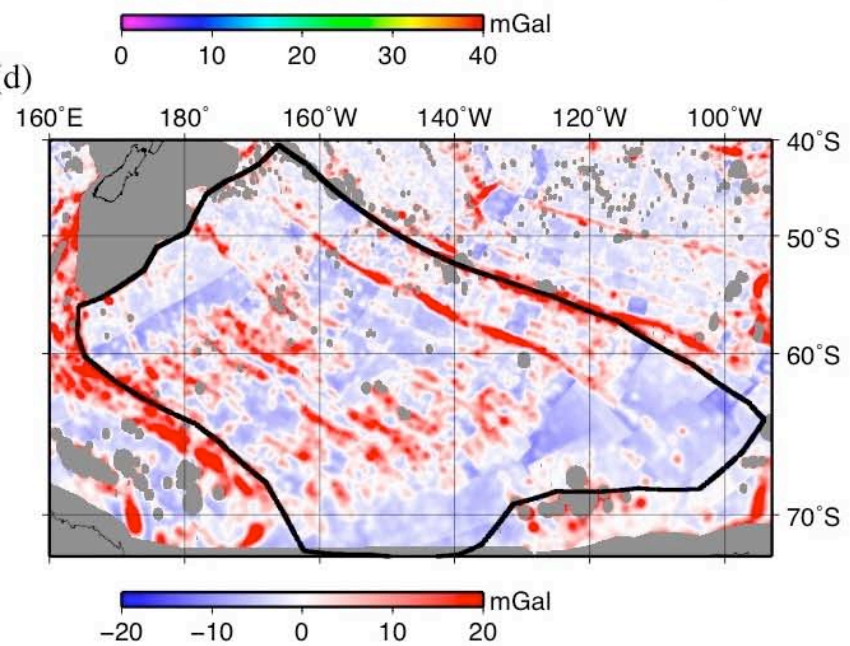

Supplementary Figure 14: South Pacific (a) gravity roughness (black dots) and residual gravity roughness (green dots) as a function of age. Predicted gravity roughness using spreading rates only (red line) and using both spreading rates and sediment thickness (blue line), (b) spreading rate (black dots) and sediment thickness (green dots) as a function of age. Roughness, residual roughness, spreading rate and sediment thickness values obtained by calculating the median and median absolute deviation in bins sized $5 \mathrm{Myr}$, (c) gravity roughness, and (d) residual gravity roughness. The residual roughness grid is computed using the gravity roughness grid, sediment thickness grid, and the spreading rate grid, which is based on constant spreading between isochrons. 
(a)

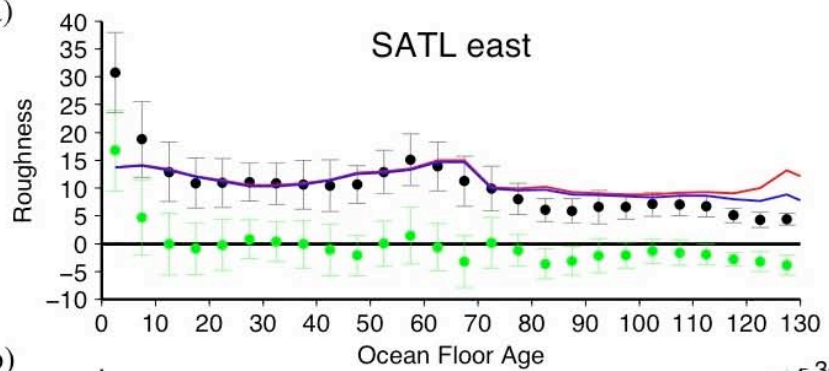

(b)

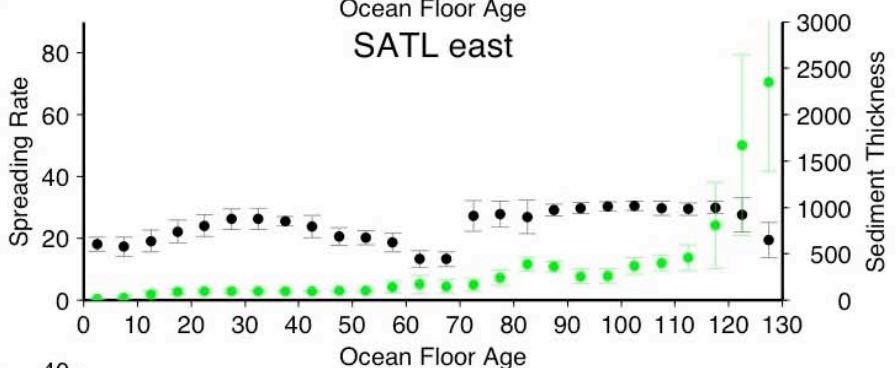

(c)

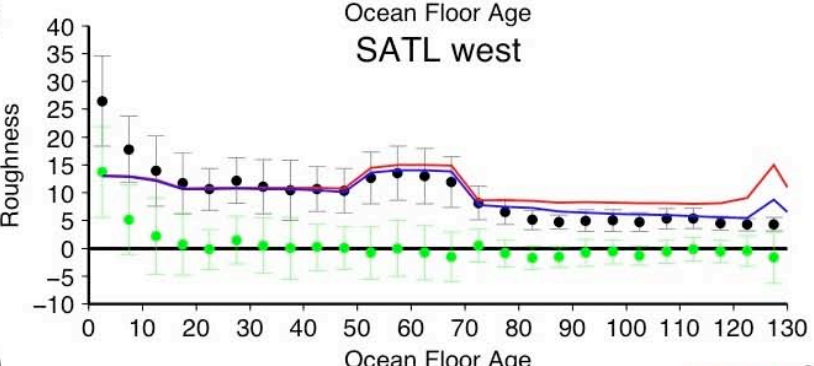

(d)

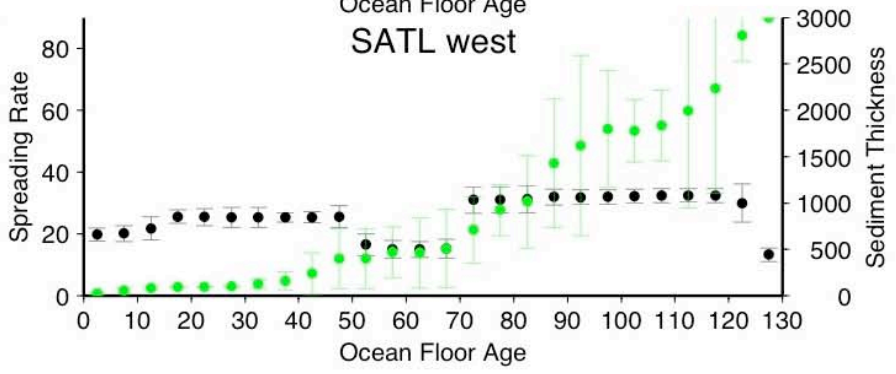

(e)

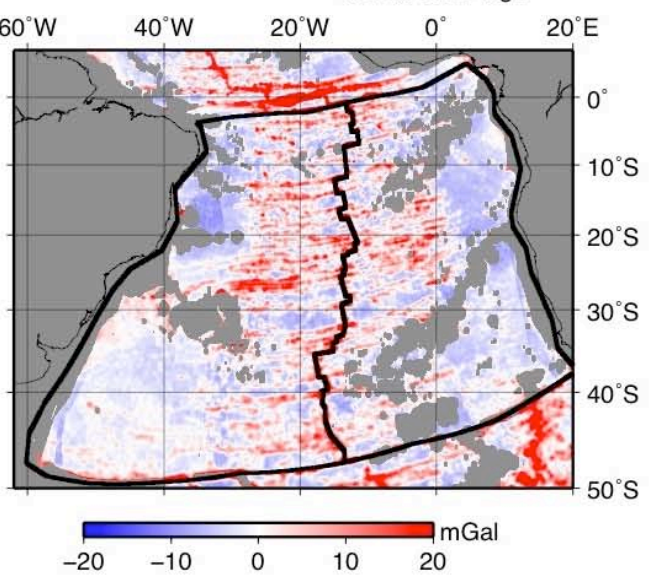

Supplementary Figure 15: South Atlantic individual flank analysis (a) and (c) gravity roughness (black dots) and residual gravity roughness (green dots) as a function of age. Predicted gravity roughness using spreading rates only (red line) and using both spreading rates and sediment thickness (blue line), (b) and (d) spreading rate (black dots) and sediment thickness (green dots) as a function of age. Roughness, residual roughness, spreading rate and sediment thickness values obtained by calculating the median and median absolute deviation in bins sized 5 Myr. (e) residual gravity roughness with locations of east and west flanks outlined in black. 
(a)

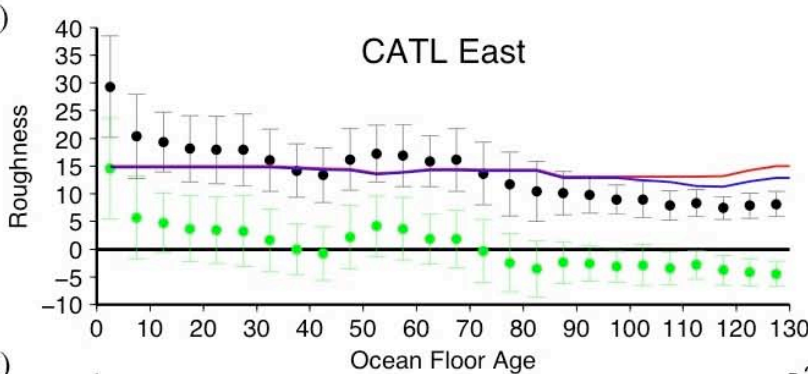

(b)

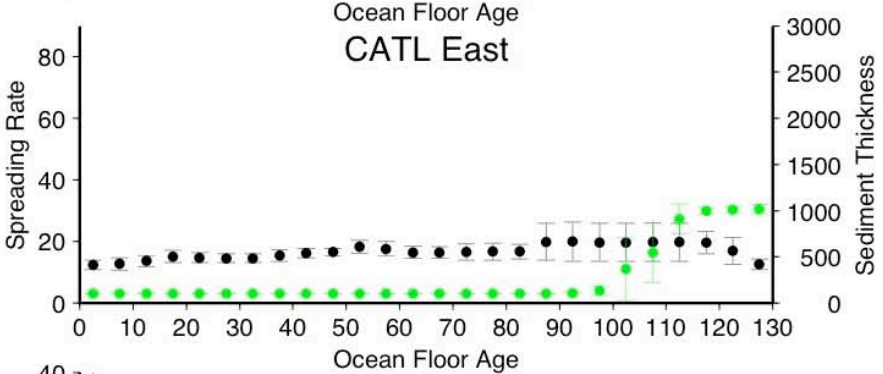

(c)

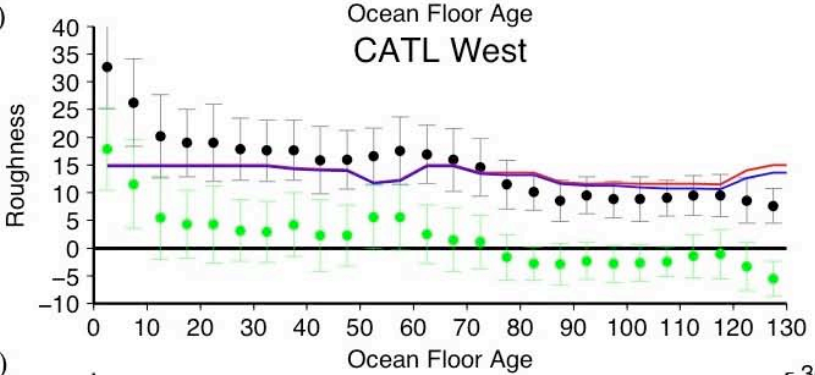

(d)

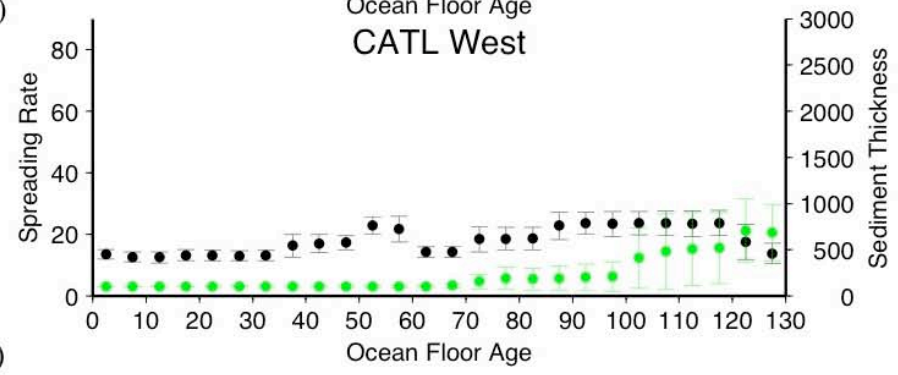

(e)

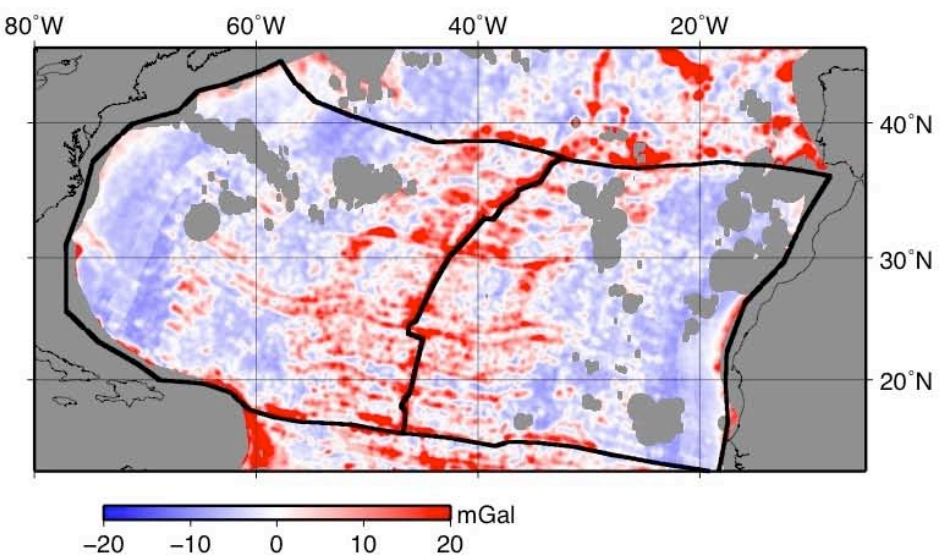

Supplementary Figure 16: Central Atlantic individual flank analysis (a) and (c) gravity roughness (black dots) and residual gravity roughness (green dots) as a function of age. Predicted gravity roughness using spreading rates only (red line) and using both spreading rates and sediment thickness (blue line), (b) and (d) spreading rate (black dots) and sediment thickness (green dots) as a function of age. Roughness, residual roughness, spreading rate and sediment thickness values obtained by calculating the median and median absolute deviation in bins sized 5 Myr. (e) residual gravity roughness with locations of east and west flanks outlined in black. 


\section{Methods}

We use a global grid of gravity anomalies based on satellite altimetry, downward continued and draped onto the lowpass of the topo_8.2.img grid of the seafloor ${ }^{30,4}$, using the filters described in Smith and Sandwell ${ }^{31}$ to create a global grid of oceanic basement roughness. Our roughness filter is a variable-width Gaussian filter adjusted to the local scale of the Mercator-projected data, whose half-power point wavelength is $50 \mathrm{~km}$, reflecting gravity anomalies due to uncompensated basement topography, implemented in the Generic Mapping Tools program grdfilter. This weighted-average filter is applied to individual points to compute root mean square (RMS) marine gravity roughness. In order to separate the effects of processes related to seafloor spreading, we mask roughness attributable to intraplate seamount trails and large igneous provinces using a masks from Wesse ${ }^{28}$ and Coffin and Eldholm ${ }^{29}$. The mapped seamount radii are multiplied by a factor of 2.5 to mask out flexural effects from seamount emplacement.

Analysis of the relationship between gravity-derived roughness and spreading rateand sediment thickness were conducted using global grids of sediment thickness ${ }^{13}$, halfspreading rates ${ }^{7}$, and oceanic basement roughness. All grids had the same mask of continental crust, seamounts ${ }^{28}$ and LIPS ${ }^{29}$ applied.

The residual roughness grid was calculated by removing the effects of spreading rate and sediment thickness from the gravity-derived roughness grid. The linear relationships between spreading rate and sediment thickness and gravity-derived roughness (Figure 2) were used to create a predicted roughness grid, which was then subtracted from the RMS gravity-derived roughness grid.

Ten regions were selected to investigate the relationship between roughness and spreading obliquity. Regions were selected to intentionally exclude triple-junctions, small/temporary spreading centres, back-arc basins and areas with complex spreading histories. The 2-minute obliquity grids were computed by calculating the difference between the regional plate motion direction (derived from the plate tectonic model of Muller et al. ${ }^{7}$ ) and the normal to the regional strike of the reconstructed mid-ocean ridge based on Muller et al. ${ }^{7}$, in 5 million year stages. All relevant digital grids can be downloaded from www.earthbyte.org.

30 Sandwell, D. T. and Smith, W. H. F., Marine gravity anomaly from Geosat and ERS-1 satellite altimetry. J. Geophys. Res. 102 (B5), 10039 (1997).

31 Smith, W.H.F. and Sandwell, D.T., Bathymetric prediction from dense satellite altimetry and sparse shipboard bathymetry. J. Geophys. Res. 99, 21803 (1994). 